\title{
Investigating the role of dust in ice nucleation within clouds and further effects on the regional weather system over East Asia - Part 2: modification of the weather system
}

\author{
Lin $\mathrm{Su}^{1}$ and Jimmy C. H. Fung ${ }^{2,3}$ \\ ${ }^{1}$ School of Science, Hong Kong University of Science and Technology, Hong Kong, China \\ ${ }^{2}$ Division of Environment, Hong Kong University of Science and Technology, Hong Kong, China \\ ${ }^{3}$ Department of Mathematics, Hong Kong University of Science and Technology, Hong Kong, China
}

Correspondence: Lin Su (lsu@ connect.ust.hk)

Received: 12 August 2017 - Discussion started: 13 October 2017

Revised: 25 July 2018 - Accepted: 2 August 2018 - Published: 15 August 2018

\begin{abstract}
An updated version of the Weather Research and Forecast model coupled with Chemistry (WRF-Chem) was applied to quantify and investigate the full effects of dust on the meteorological field over East Asia during March and April 2012. The performances of the model in simulating the shortwave and longwave radiation, surface temperature, and precipitation over East Asia are improved by incorporating the effects of dust in the simulations. The radiative forcing induced by the direct radiative effect of dust is greater than that by the dust-enhanced cloud radiative effect. The indirect effects of dust result in a substantial increase in ice clouds at the middle to upper troposphere and a reduction in liquid clouds at the low to mid-troposphere. The radiative forcing combined with the redistribution of atmospheric water vapor results in an overall decrease in near-surface temperature and an increase in temperature at the middle to upper troposphere over East Asia, leading to an inhibition of atmospheric instability over most land areas, but an enhancement of atmospheric instability over south China. Upon considering the effects of dust, convective precipitation exhibits an inhibition over areas from central to east China and an enhancement over south China. Meanwhile, the locations of non-convective precipitation are shifted due to the perturbation of cloud water path. The total amount of precipitation over East Asia remains unchanged; however, the precipitation locations are shifted. The precipitation can be enhanced or inhibited by up to $20 \%$ at particular areas.
\end{abstract}

\section{Introduction}

Dust is recognized as an "essential climate variable" because it is a major component of atmospheric aerosols and has significant impacts on the weather and climate system (Solomon, 2007). East Asian dust is an important contributor to global dust emissions (Ginoux et al., 2001) and thus plays a significant role in affecting the regional weather system through direct, semi-direct, and indirect effects.

Dust particles affect the radiation budget directly by absorbing, reflecting, and scattering shortwave and longwave radiation (Satheesh et al., 2006; Seinfeld et al., 2004; Lacis, 1995). The absorption of radiation by dust can further affect atmospheric static stability and the surface energy budget, which may lead to an evaporation of cloud droplets. This effect is referred as a semi-direct effect of dust (Solomon, 2007). The indirect effects of dust are related to dust-cloud interaction (Hansen et al., 1997; Perlwitz and Miller, 2010). Dust particles are recognized as effective ice nuclei (IN) and considered to play an important role in cold cloud processes (Broadley et al., 2012; Connolly et al., 2009; Sassen, 2002), leading to variation in the ice water content in mixed-phase and ice clouds, which further affects the formation and development of clouds, as well as precipitation (Sassen et al., 2003; Targino et al., 2006; Teller and Levin, 2006; Lohmann and Feichter, 2005).

In light of the significance of dust for the weather and climate system, assessing the effects of dust has become increasingly important. On the one hand, the direct (Mallet et al., 2009; Nabat et al., 2015a; Ge et al., 2010; Hartmann 
et al., 2013; Huang et al., 2009; Bi et al., 2013; Liu et al., 2011a, b; Palacios et al., 2015; Chen et al., 2017) and semidirect (Tesfaye et al., 2015; Nabat et al., 2015b; Seigel et al., 2013) effects of dust have being extensively studied worldwide by applying numerical methods. On the other hand, various ice nucleation parameterizations have been implemented into global models to estimate the importance of dust in atmospheric ice nucleation (Lohmann and Diehl, 2006; Karydis et al., 2011; Hoose et al., 2008; Zhang et al., 2014), revealing that the effect of dust as IN should not be neglected in numerical models, especially in simulations over arid regions during strong wind events (DeMott et al., 2003, 2015; Koehler et al., 2010; Lohmann and Diehl, 2006; Atkinson et al., 2013). Unfortunately, only limited work has been carried out to investigate the indirect effects of dust on the regional weather system, especially over East Asia, which is one of the major contributors to global dust emissions (Ginoux et al., 2001).

This series of studies aimed to investigate the role of East Asian dust in affecting the regional weather system. In the first part of the study, the Goddard Chemistry Aerosol Radiation and Transport (GOCART) model was coupled with the aerosol-aware Thompson-Eidhammer microphysics scheme (Thompson and Eidhammer, 2014), enabling the model to estimate the indirect effect of dust along with the direct and semi-direct effects, which improved the simulation of the ice nucleation process involving dust particles ( $\mathrm{Su}$ and Fung, 2015). In this work, by applying an updated version of WRFChem, we aim to investigate the full effects of dust, including direct, semi-direct, and indirect effects, on the regional weather system over East Asia during a dust-intensive period. As the semi-direct effect and indirect effect of dust cannot be separated in our simulation, these two effects are merged and discussed as a part of the effects of dust apart from the direct effect and represented by "indirect effects" in the rest of the paper. This is the first study to document the full effects of dust during a typical dust-intensive period over East Asia by applying an online coupled regional numerical model.

The remainder of the paper is organized as follows. The model configuration is described in Sect. 2, followed by the model validation in Sect. 3. The results along with the discussion will be presented in Sect. 4, followed by the concluding remarks in Sect. 5.

\section{Model configurations}

The simulations were performed using an updated version of WRF-Chem based on version 3.8.1 (Peckham et al., 2017). GOCART-Thompson, which is the coupling of the GOCART aerosol model and the aerosol-aware ThompsonEidhammer microphysics scheme, has been implemented in the updated WRF-Chem to evaluate the indirect effects of dust on the atmospheric ice nucleation process by serving as
IN. In the GOCART-Thompson microphysics scheme, condensation and immersion freezing are parameterized by the DeMott2015 ice nucleation scheme, and two factors of the DeMott2015 scheme were tuned through sensitivity experiments in the first part of this study. $c_{\mathrm{f}}$ is a calibration factor in the DeMott2015 ice nucleation parameterization scheme, which was used for the nucleation of the heterogeneous nucleation of ice crystals by dust particles in the GOCARTThompson scheme, and it ranges from 1 to 6 . According to the results of the sensitivity experiments in Part I, the calibration factor $c_{\mathrm{f}}$ was set to be 4 for the simulations in this study. Furthermore, it was also demonstrated that ice water content was still underestimated by using the GOCART-Thompson scheme. To improve the simulation of ice nucleation by dust particles, the threshold relative humidity with respect to ice $\left(\mathrm{RH}_{\mathrm{i}}\right)$ was lowered from 105 to $100 \%$ in the ice nucleation parameterization to allow for the heterogeneous nucleation of ice crystals by dust particles to occur at a lower $\mathrm{RH}_{\mathrm{i}}(\mathrm{Su}$ and Fung, 2017). Therefore, a threshold $\mathrm{RH}_{\mathrm{i}}$ of $100 \%$ for the simulations was run with dust emissions in this study. In addition, deposition nucleation is determined by the Phillips parameterization scheme (Phillips et al., 2008), and the freezing of deliquesced aerosols using the hygroscopic aerosol concentration is parameterized following Koop's parameterization scheme (Koop et al., 2000). The GOCART aerosol model was applied to simulate aerosol processes (Ginoux et al., 2001, 2004) and produce ice nuclei that were served by dust particles in DUST. Shao's dust emissions (Kang et al., 2011; Shao et al., 2011) with soil data from the United states Geological Survey (Soil Survey Staff, 1993), which have been demonstrated to have good performance in reproducing dust emissions over East Asia, were used to generate dust emission in the TEST simulations. The ice nuclei were then fed into the GOCART-Thompson microphysics scheme for calculating the indirect effects of dust by using the DeMott2015 parameterization scheme. In addition, the pre-given climatological profiles applied in the ThompsonEidhammer scheme (Thompson and Eidhammer, 2014) were used to provide the number concentration of water-friendly aerosols for the freezing of deliquesced aerosols to consider the background indirect effects of aerosols on ice nucleation for all the simulations in this study.

Four numerical simulations were carried out to evaluate the separate effects of dust over East Asia. The configurations for the four simulations are summarized in Table 1. The first simulation was termed NO-DUST/NO-CLOUD and was conducted without dust, with both the aerosol radiative feedback and cloud radiative feedback turned off. The second simulation, NO-DUST/CLOUD, was also conducted without dust, with the aerosol radiative feedback turned off but the cloud radiative feedback turned on to estimate the intrinsic radiative effect of cloud. The third simulation, DUST/NOCLOUD, was conducted with the presence of dust, with the aerosol radiative feedback turned on, while the cloud radiative feedback was still turned off. The difference between 
Table 1. Model configurations for the numerical simulations.

\begin{tabular}{|c|c|c|c|c|}
\hline Experiment & $\begin{array}{l}\text { NO-DUST/ } \\
\text { NO-CLOUD }\end{array}$ & $\begin{array}{l}\text { NO-DUST/ } \\
\text { CLOUD }\end{array}$ & $\begin{array}{l}\text { DUST/ } \\
\text { NO-CLOUD }\end{array}$ & $\begin{array}{l}\text { DUST/ } \\
\text { CLOUD }\end{array}$ \\
\hline \multicolumn{5}{|l|}{ Scheme } \\
\hline Dust emission scheme & - & - & Shao & Shao \\
\hline Dry deposition & - & - & $\begin{array}{l}\text { Gravitational settling and } \\
\text { surface deposition }\end{array}$ & $\begin{array}{l}\text { Gravitational settling and } \\
\text { surface deposition }\end{array}$ \\
\hline Wet deposition & - & - & In-cloud and below-cloud & In-cloud and below-cloud \\
\hline Aerosol optical scheme & - & - & Maxwell Garnett & Maxwell Garnett \\
\hline Aerosol radiative feedback & off & off & on & on \\
\hline Cloud radiative feedback & off & on & off & on \\
\hline
\end{tabular}

NO-DUST/NO-CLOUD and DUST/NO-CLOUD therefore represented the direct effect of dust on the radiation budget and other meteorological parameters. The last simulation, DUST/CLOUD, was conducted with the presence of dust and with both aerosol radiative feedback and cloud radiative feedback turned on to estimate the full effect of dust on the meteorological field over East Asia.

The important physical and chemical parameterization schemes applied for the four simulations are as follows. The GOCART aerosol model was applied to simulate aerosol processes (Ginoux et al., 2001, 2004). For the dust emission simulation in DUST/NO-CLOUD and DUST/CLOUD, the Shao dust emission scheme (Shao, 2004; Shao et al., 2011) was applied, which has been demonstrated to closely reproduce dust emissions over East Asia (Su and Fung, 2015). Note that no aerosol emissions were considered in the simulations other than dust. The Mellor-Yamada-Janjic (MYJ) turbulent kinetic energy scheme was used for the planetary boundary layer parameterization (Janjić, 1994, 2002); the moisture convective processes were parameterized by the GrellFreitas scheme (Grell and Freitas, 2014); the shortwave (SW) and longwave (LW) radiation budgets were calculated by the Rapid Radiative Transfer Model for General Circulation (RRTMG) SW and LW radiation schemes (Mlawer et al., 1997; Iacono et al., 2008); gravitational settling and surface deposition were combined for aerosol dry deposition (Wesely, 1989); a simple washout method was used for the below-cloud wet deposition of aerosols; and the aerosol optical properties were calculated based on the volumeaveraging method. The newly implemented wet scavenging scheme described in Part 1 of this study was used for the incloud wet scavenging of dust particles caused by microphysical processes. As no dust was simulated in NO-DUST/NOCLOUD and NO-DUST/CLOUD, these two simulations did not include a dust emission scheme, aerosol dry and wet deposition schemes, or aerosol optical schemes.

As described in the first part of this paper, two nested domains were used for all four simulations. The outer domain had a horizontal resolution of $27 \mathrm{~km}$, covering the entire East Asia region, and the inner domain had a horizontal resolution of $9 \mathrm{~km}$, covering the entirety of central to east China. Both domains have 40 layers, with the top layer at $50 \mathrm{hPa}$. The simulation period was 9 March to 30 April 2012, with the first 8 days as "spin-up" time. Only the results from 17 March to 30 April 2012 were used for further analysis. Final reanalysis data provided by the United States National Center of Environmental Prediction, with a horizontal resolution of $1^{\circ}$, were used for generating the initial and boundary conditions for the meteorological field. The simulations were reinitialized every 4 days, with the aerosol field being recycled; i.e., the output of the aerosol field from the previous 4-day run was used as the initial aerosol state for the next 4-day run.

\section{Model validation}

The simulation for dust emissions was validated in Part 1 of this study, and the model was demonstrated to closely reproduce dust emissions over East Asia during the investigated period by comparison with comprehensive observational data. As this study focused on the modification of the meteorological field by the effects of dust over East Asia, the capability of the model to simulate the meteorological field itself over this region requires further validation.

The China Meteorological Forcing Dataset (Yang et al., 2010; Chen et al., 2011) was used to assess the performance of the model in reproducing the spatial distribution of the meteorological field over China. The dataset was developed by the hydrometeorological research group at the Institute of Tibetan Plateau Research, Chinese Academy of Science, by merging the Princeton meteorological forcing data (Sheffield et al., 2006), the Global Energy and Water Cycle Experiment-Surface Radiation Budget (GEWEXSRB) forcing data (Pinker and Laszlo, 1992), and the Global Land Data Assimilation System forcing dataset (Rodell et al., 2004). The dataset contains gridded observations of the nearsurface temperature, precipitation rate, and surface downward SW and LW radiation across China, with a spatial resolution of $0.25^{\circ}$ dating from 1996.

Note that only simulation results from NODUST/CLOUD and DUST/CLOUD are shown, as they 
represent the intrinsic meteorological field and the meteorological field modified by the effects of dust, respectively. For March, the comparison is restricted to the observational data from 17 to 31 March 2012 to ensure temporal overlay with the corresponding simulation period. No observational data over the ocean were available, so the simulated results over the ocean are also omitted to simplify the comparison.

The spatial distributions for the monthly average observational downward surface SW radiation for March and April 2012 are shown in Fig. 1a and b. Overall, the SW radiation was stronger in April than in March. The SW radiation was significantly higher over western and northwestern China due to the higher elevation of terrain over these regions and lower over east and south China due to the lower elevation and greater cloud coverage over those regions. The model closely reproduced the spatial distributions of SW radiation in both months and accurately captured the trend from March to April in the simulation results from both NODUST/CLOUD and DUST/CLOUD despite a certain overestimation, especially over coastal areas in east and south China. This overestimation was likely due to the underestimation of clouds by the model over these areas. Compared with inland areas, cloud coverage is always greater over the coastal areas of east and south China due to the abundant water vapor. Therefore, the SW radiation budget over coastal areas was more sensitive to the underestimation of clouds by the model. Nevertheless, an improvement in the simulation of the SW radiation budget over East Asia can be seen in the results from DUST/CLOUD compared with those from NODUST/CLOUD. Specifically, the SW radiation produced in DUST/CLOUD (Fig. 1e and f) was substantially lower than that produced in NO-DUST/CLOUD (Fig. 1c and d) over China, especially at the dust sources and surrounding areas over the north and northwest of the country, which is clearly more consistent with the observations.

For downward surface LW radiation, two high-value areas can be observed (Fig. 2a and b). One is over northwest China, where the Taklimakan Desert is located. The strong downward LW radiation over this region was likely due to the abundance of dust particles in the local atmosphere. The other area of strong LW radiation was located over south China, which is warmer and contains more atmospheric water vapor. Water vapor is a potent greenhouse gas, which efficiently absorbs LW radiation emitted by the Earth, heats the surrounding area, and thus increases the emission of LW radiation downward (and upward) by the heated atmosphere. The model accurately simulated the spatial distributions of LW radiation over this region for both March and April in both NO-DUST/CLOUD (Fig. $2 \mathrm{c}$ and d) and DUST/CLOUD (Fig. 2e and f) and indeed closely captured the spatial pattern of LW radiation over China. The LW radiation over the Gobi Desert produced by DUST/CLOUD (Fig. 2e and f) is slightly higher than that produced by NO-DUST/CLOUD, indicating that the model reproduced the LW radiation bud- get more accurately upon taking the effects of dust into account.

Similarly to the spatial distributions for LW radiation, higher near-surface temperatures were observed over northwest China, which is a dry, arid area, and south China, which is closer to the Equator (Fig. 3a and b). The spatial distributions of the near-surface temperature over this region were well reproduced by the model for both March and April in both NO-DUST/CLOUD (Fig. 3c and d) and DUST/CLOUD (Fig. 3e and f). The model accurately captured the spatial pattern of the surface temperature, and the two simulations did not show remarkable difference in their results.

During the simulation period, precipitation increased from north to south China in both months and increased from March to April over the entire region (Fig. 4a and b). The spatial patterns of precipitation in March and April were mostly reproduced by the model in both NO-DUST/CLOUD (Fig. 4c and d) and DUST/CLOUD (Fig. 4e and f), but the model underestimated the precipitation in March in both simulations, especially over central and north China. In April, the observed precipitation center was located over south China. Apart from underestimating the precipitation over central and north China, the NO-DUST/CLOUD simulation predicted the precipitation center to be located in an area to the north of the observed center (Fig. 4d), and it also underestimated the precipitation over south China. In contrast, in the results of DUST/CLOUD (Fig. 4f), the precipitation band to the north of south China was weaker, and the precipitation over south China was slightly stronger than that produced by NO-DUST/CLOUD, which was more consistent with the observations.

The comparison of the simulation results with the observational data demonstrated that the model reasonably reproduced the meteorological field over East Asia. Moreover, the meteorological field was produced more accurately when the effects of dust were considered in the simulations, which consequently allows the dust-induced modification of the meteorological field to be investigated.

\section{Results and discussion}

\subsection{Atmospheric water vapor}

\subsubsection{Spatial distribution}

The indirect effects of dust particles lead to modifications of cloud properties and cloud lifetime and a redistribution of atmospheric water vapor. The spatial distributions of the simulated ice water path (IWP) and cloud water path (CWP) from NO-DUST/CLOUD and DUST/CLOUD and the difference between the two simulations (DUST/CLOUD-NODUST/CLOUD) are presented in Fig. 5. The atmospheric IWP and CWP are the column sums of cloud ice water content and cloud water content in the atmosphere per unit area. 


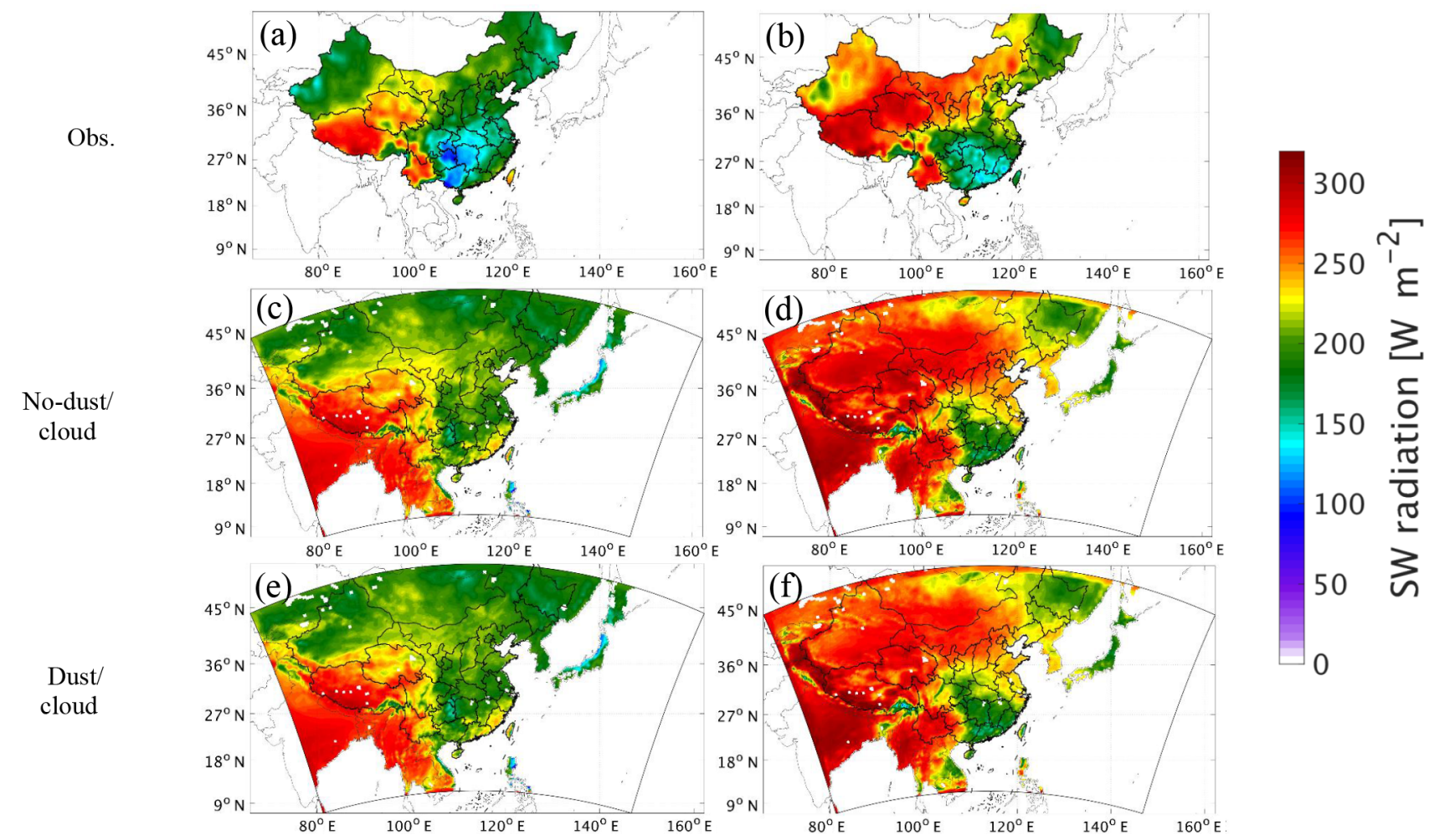

Figure 1. Spatial distributions of the average downward SW radiation at the surface from observations (a, b), from NO-DUST/CLOUD (c, d), and from DUST-CLOUD (e, f) during March (left panels) and April (right panels) 2012.

Note that the difference between NO-DUST/CLOUD and DUST/CLOUD is entirely due to the full effects of dust, i.e., the direct effect of dust, the cloud radiative effect enhanced by dust, and the microphysical effect of dust serving as IN in the atmosphere. The spatial distributions shown in Fig. 5 are the mean IWP and CWP averaged over the whole simulation period.

Figure 5a and $\mathrm{b}$ show the spatial distributions of the mean atmospheric IWP over East Asia produced from NODUST/CLOUD and DUST/CLOUD. The IWP is concentrated over midlatitude areas $\left(30-40^{\circ} \mathrm{N}\right)$ in the results of NODUST/CLOUD (Fig. 5a), with values of $10-20 \mathrm{~g} \mathrm{~m}^{-2}$. These ice crystals are mostly formed through the freezing of deliquesced water-friendly aerosols. By contrast, the IWP produced by DUST/CLOUD is substantially higher than that produced by NO-DUST/CLOUD over midlatitude areas in the simulation domain, which are the dust sources and their downstream areas (Fig. 5b). This corresponds to an increase by 25 to $50 \%$ over vast areas from dust source regions to the northwest Pacific (Fig. 5c) due to the dust particles serving as IN and leading to a substantial enhancement of ice crystals in the atmosphere. Dust nuclei in the atmosphere enable the supercooled water droplets to freeze into ice crystals at a much higher temperature and lower relative humidity.

The spatial distributions for the mean CWP over East Asia produced from NO-DUST/CLOUD and DUST/CLOUD are shown in Fig. 5d and e, in both of which the CWPs are concentrated over south China and the western Pacific Ocean, with comparable values to each other. However, the comparison of CWPs produced from DUST/CLOUD and NODUST/CLOUD in Fig. $5 \mathrm{f}$ shows that the existence of dust leads to a slight reduction of CWP over west, north, and central China, where the IWP increases substantially. Moreover, there are perturbations of CWP over east and south China, as well as the western Pacific Ocean. Particularly, the CWP is generally reduced by up to $10 \mathrm{~g} \mathrm{~m}^{-2}$ over west, north, and central China and increased by up to $10 \mathrm{~g} \mathrm{~m}^{-2}$ over south China, which accounts for over $10 \%$ of the total cloud water vapor at these regions.

\subsubsection{Vertical profile}

As the spatial distributions of IWP and CWP over East Asia are altered by the effects of dust, the cloud ice mixing ratio and cloud water mixing ratio are also modified vertically. Figure 6 shows the modifications on vertical profiles of the cloud ice and cloud water mixing ratios induced by the full effects of dust. Note that the vertical profiles over land, over the ocean, and over the entire simulation domain for East Asia are averaged across the whole simulation period.

Due to the effects of dust, the cloud ice mixing ratio is increased at all altitudes from the near-surface layer to higher 


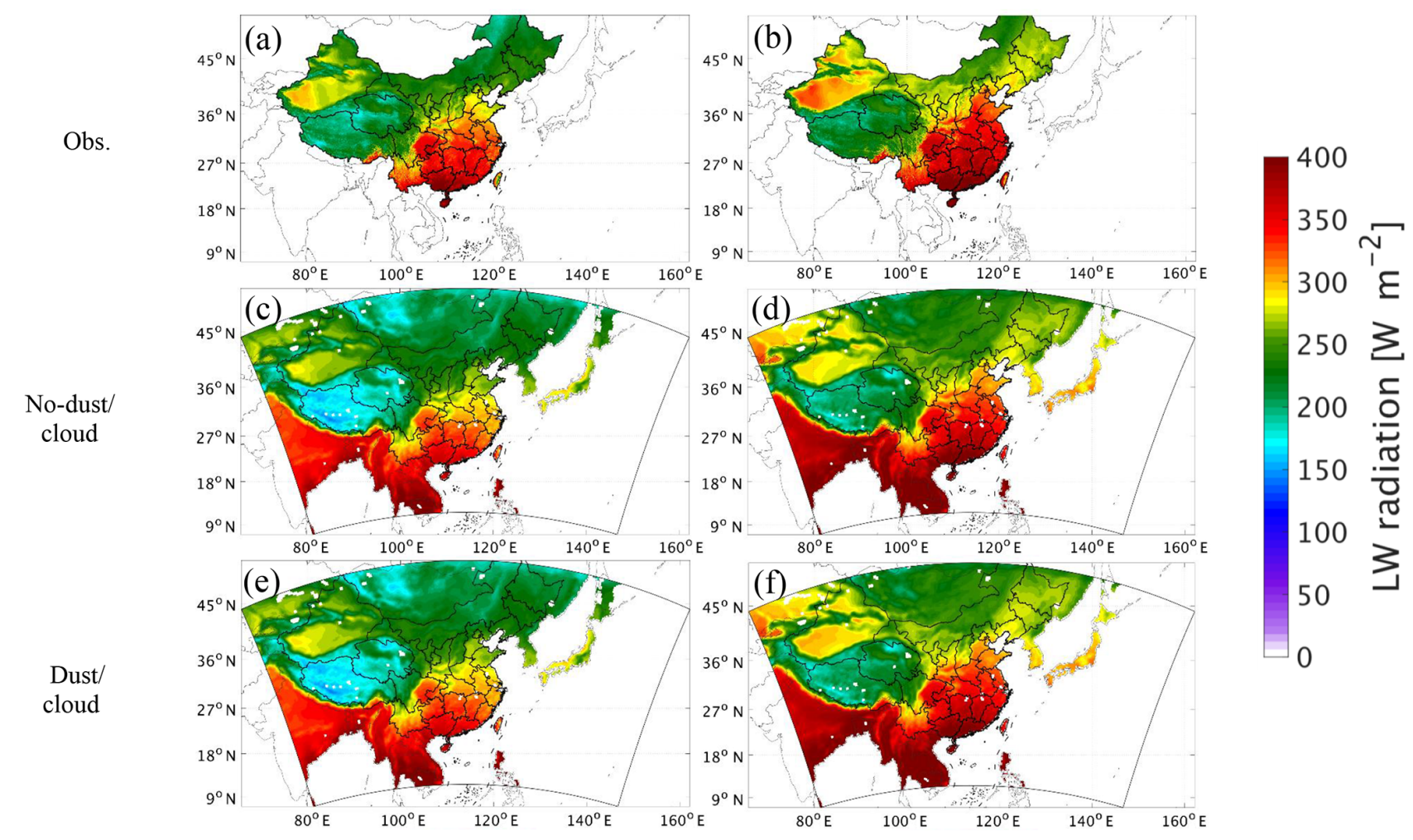

Figure 2. Spatial distributions of the average downward LW radiation at the surface from observations (a, b), from NO-DUST/CLOUD (c, d), and from DUST-CLOUD (e, f) during March (left panels) and April (right panels) 2012.

than $10 \mathrm{~km}$ over the whole of East Asia, as shown in Fig. 6a. The cloud ice mixing ratio is uniformly increased between the surface and $10 \mathrm{~km}$ over land with a peak located at around $7 \mathrm{~km}$ (Fig. 6b), which results from the increase in IN served by the abundant dust particles in the atmosphere. In contrast, the increase in the cloud ice mixing ratio over the ocean is much less significant, with a higher peak located at 8 $9 \mathrm{~km}$ (Fig. 6c). A possible cause of the higher peak over the ocean is that only those particles small enough to be lifted to high altitudes can be transported as far as the open ocean of the west Pacific, whereas over land, more dust particles with larger sizes are suspended in lower layers before settling down to the surface.

The vertical modification of the cloud water mixing ratio due to the effects of dust is fundamentally different from that of the cloud ice mixing ratio. Due to the effects of dust, the cloud water mixing ratio shows a decrease on average over East Asia from the surface to $7 \mathrm{~km}$ (Fig. 6d). The overall decrease is dominated by the reduction in the cloud water mixing ratio over land (Fig. 6e). The cloud water mixing ratio is also decreased over the ocean near surface and above $4 \mathrm{~km}$, but slightly increase between 1 and $4 \mathrm{~km}$ (Fig. 6f). The vertical modification of the cloud water mixing ratio suggests that the effects of dust reduce liquid clouds at the low to midtroposphere over East Asia, especially over land.
To summarize, the effects of dust result in a general increase in ice clouds and a slight decrease in liquid clouds over East Asia as a whole, whereby the increase in cloud ice is mainly concentrated at the middle to upper troposphere, while the decrease in cloud water mostly occurs in low- and mid-altitude clouds.

The increase in ice clouds at the middle to upper troposphere is attributed to the indirect effects of dust. The abundant IN in the atmosphere served by dust particles substantially increase the amount of ice crystals in mixed-phase and ice clouds at these altitudes. In contrast, the decrease in liquid clouds at the low to middle troposphere is the result of two factors. One is the warming within the atmosphere induced by the dust, leading to a much higher saturation pressure required for atmospheric water vapor to form clouds and a much faster evaporation rate of cloud droplets, which is due to the cloud burning effect of dust. The other factor is that the supercooled cloud droplets in the upper layers of the troposphere freeze into ice crystals at a much higher temperature and lower relative humidity when dust particles serve as IN in the atmosphere, leading to an increase in atmospheric IWP. Combined with the direct radiative effect of dust, the modifications of ice and liquid clouds induced by dust will alter the radiation budget over the region. Compared to that of the increase for the ice clouds, the magnitude of the decrease for liquid clouds is smaller. However, the radiative effect of liq- 


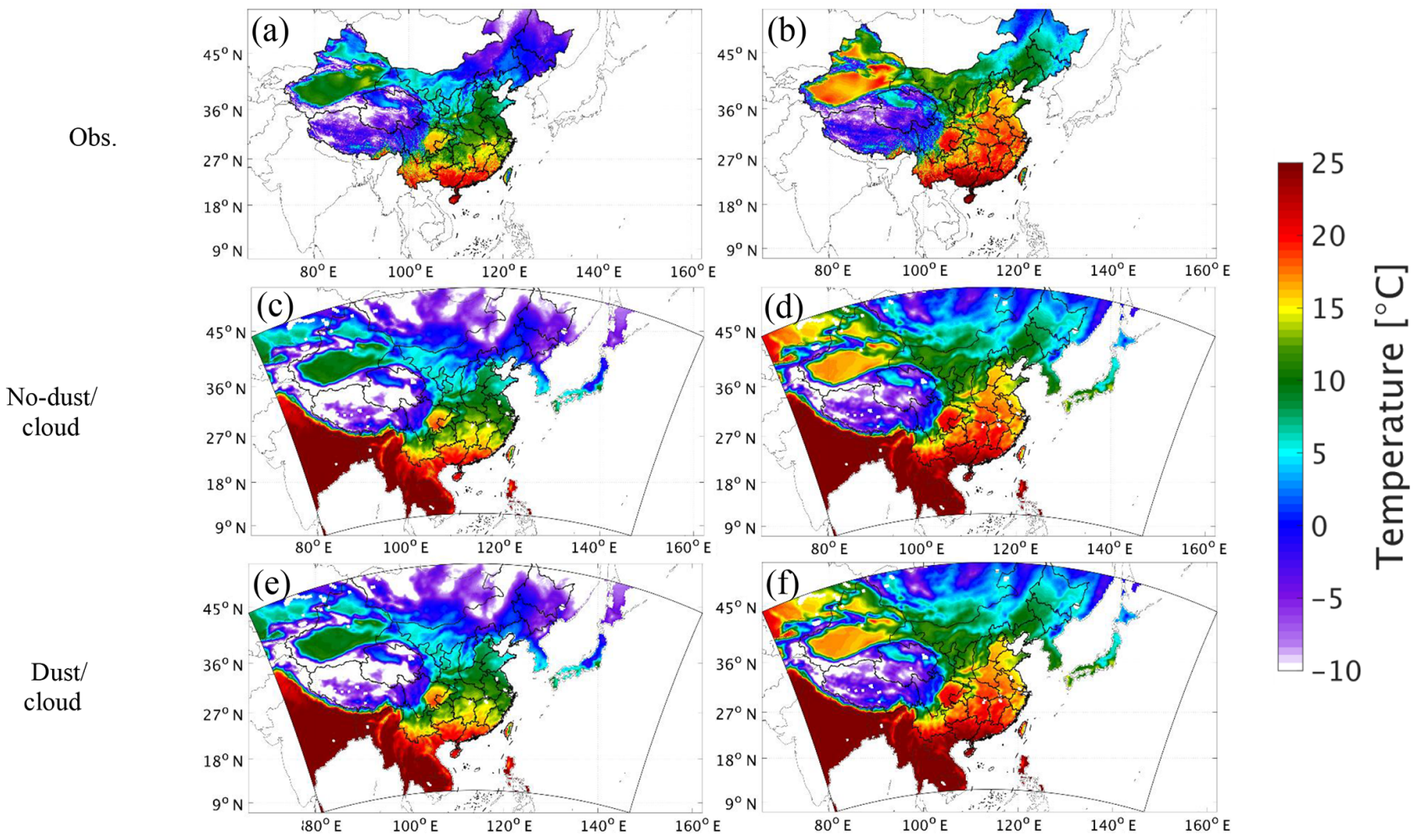

Figure 3. Spatial distributions of the average near-surface temperature from observations (a, b), from NO-DUST/CLOUD (c, d), and from DUST-CLOUD (e, f) during March (left panels) and April (right panels) 2012.

uid clouds, especially low clouds, is much greater than that of ice clouds; therefore, the decrease in liquid clouds might have a greater impact on the radiative budget over East Asia, which will be discussed in the following section.

\subsection{Radiative effect}

The radiative effect of dust particles is demonstrated by dustinduced SW, LW, and net radiative forcing at the top of the atmosphere (TOA), at the bottom of the atmosphere (BOT), and within the atmosphere (ATM). In this study, the dustinduced radiative effect is represented by the difference between the SW, LW, and net radiative budget produced from NO-DUST/CLOUD and DUST/CLOUD, both of which output clear-sky and all-sky SW and LW radiation budget.

The spatial distributions for the mean radiative forcing induced by dust at the top of the atmosphere, at the bottom of the atmosphere, and within the atmosphere over East Asia during the simulation period are shown in Figs. 7 and 8. Note that all of the spatial distributions for radiative forcing shown in the two figures are the temporal mean over the entire simulation period. The SW radiative forcing was calculated as follows.

$\mathrm{SW}_{\mathrm{TOA}}=\mathrm{SWDOWN}_{\mathrm{TOA}}-\mathrm{SWUP}_{\mathrm{TOA}}$

$\mathrm{SW}_{\mathrm{BOT}}=\mathrm{SWDOWN}_{\mathrm{BOT}}-\mathrm{SWUP}_{\mathrm{BOT}}$
$\mathrm{SW}_{\mathrm{ATM}}=\mathrm{SW}_{\mathrm{TOA}}+\mathrm{SW}_{\mathrm{BOT}}$,

$\mathrm{SW}_{\mathrm{TOA}}$ is the SW radiative forcing at the top of the atmosphere, and $\mathrm{SW}_{\mathrm{BOT}}$ is the $\mathrm{SW}$ radiative forcing at the bottom of the atmosphere, both with positive values representing downwelling radiation. $\mathrm{SW}_{\mathrm{ATM}}$ is the radiative forcing within the atmosphere, which is the sum of $\mathrm{SW}_{\mathrm{TOA}}$ and $\mathrm{SW}_{\mathrm{BOT}}$, with positive values representing a net warming effect within the atmosphere. SWDOWN $\mathrm{TOA}_{\mathrm{TOA}}$ and SWUP $\mathrm{TOA}_{\mathrm{T}}$ are the downwelling and upwelling SW radiation at the top of the atmosphere, respectively, and SWUP $_{\mathrm{BOT}}$ and SWDOWN $\mathrm{N}_{\text {BOT }}$ are the upwelling and downwelling SW radiation at the bottom of the atmosphere, respectively.

The LW radiative forcing was calculated as follows.

$$
\begin{aligned}
& \mathrm{LW}_{\mathrm{TOA}}=-\mathrm{LWUP}_{\mathrm{TOA}} \\
& \mathrm{LW}_{\text {BOT }}=\mathrm{LWDOWN}_{\mathrm{BOT}}-\mathrm{LWUP}_{\mathrm{BOT}} \\
& \mathrm{LW}_{\mathrm{ATM}}=\mathrm{LW}_{\mathrm{TOA}}+\mathrm{LW}_{\mathrm{BOT}} .
\end{aligned}
$$

$\mathrm{LW}_{\mathrm{TOA}}$ is the LW radiative forcing at the top of the atmosphere, and $\mathrm{LW}_{\mathrm{BOT}}$ is the LW radiative forcing at the bottom of the atmosphere, both with positive values representing downwelling radiation. $\mathrm{LW}_{\mathrm{ATM}}$ is the radiative forcing within the atmosphere, which is the sum of $\mathrm{LW}_{\mathrm{TOA}}$ and $\mathrm{LW}_{\mathrm{BOT}}$, with positive values representing warming effect within the atmosphere. LWUP $_{\mathrm{TOA}}$ is the upwelling $\mathrm{LW}$ radiation at the top of the atmosphere, and LWUP BOT $_{\text {and }}$ 


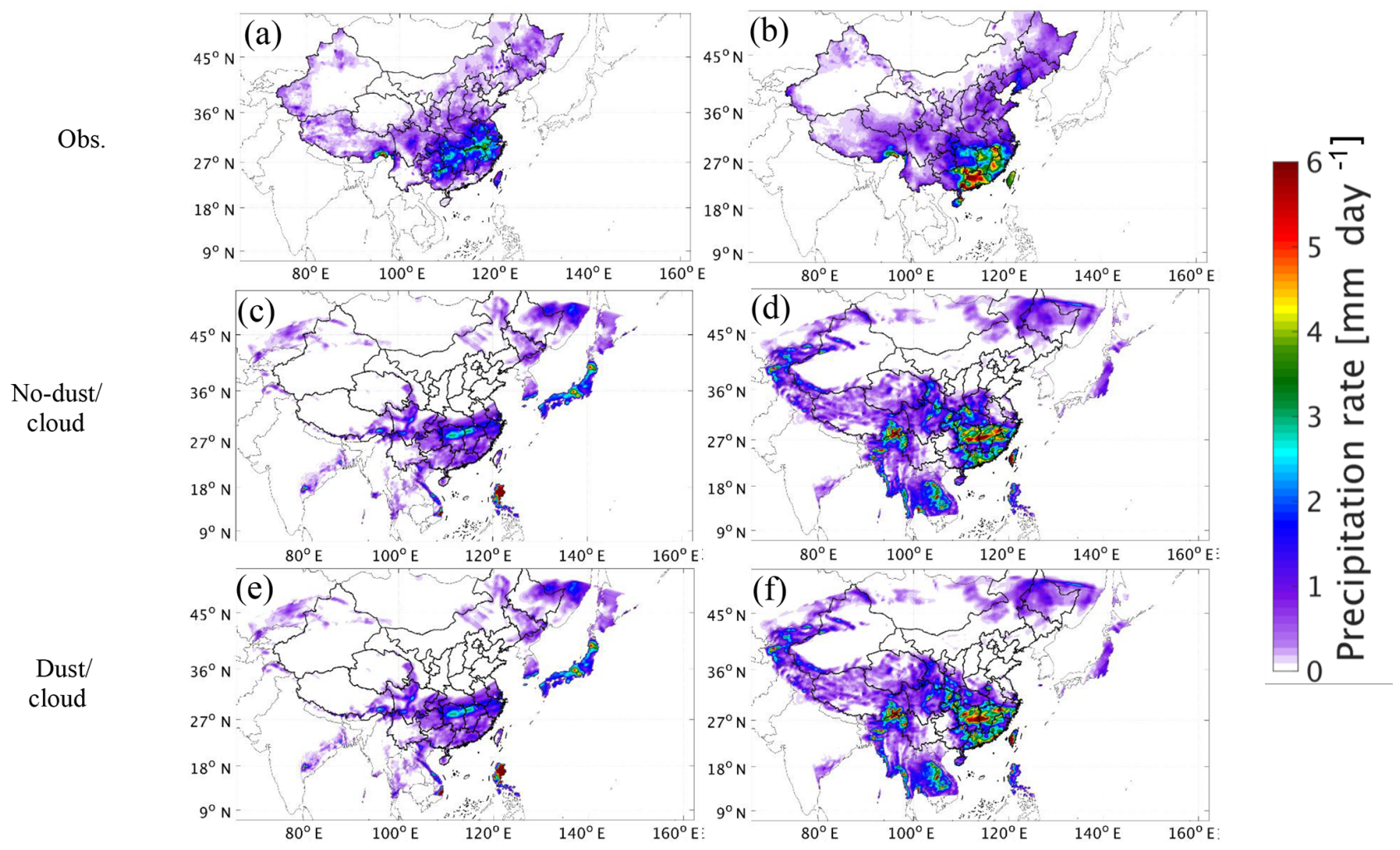

Figure 4. Spatial distributions of the average precipitation rate from observations (a, b), from NO-DUST/CLOUD (c, d), and from DUST/CLOUD (e, f) during March (left panels) and April (right panels) 2012.
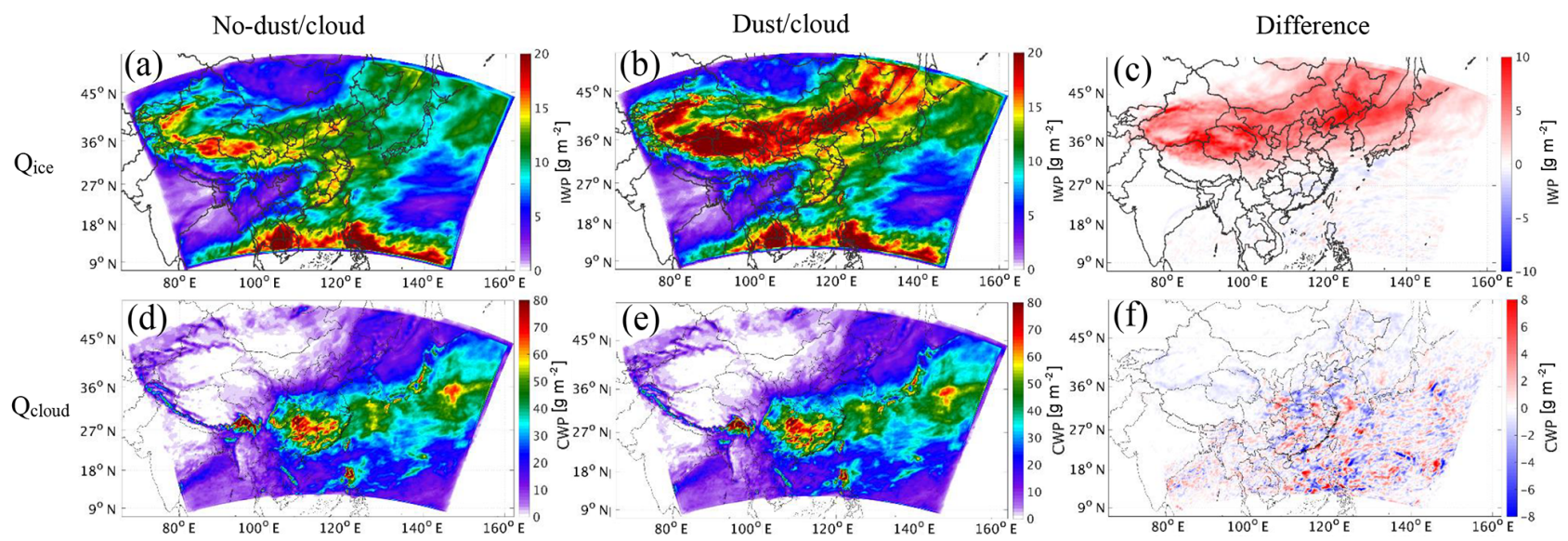

Figure 5. Spatial distributions of the average simulated IWP (a-c) and CWP (d-f) from NO-DUST/CLOUD (left panels), DUST/CLOUD (middle panels), and the difference between DUST/CLOUD and NO-DUST/CLOUD (right panels).

LWDOWN $\mathrm{N}_{\text {BOT }}$ are the upwelling and downwelling LW radiation at the bottom of the atmosphere.

The net radiative forcing is the sum of SW and LW radiative forcing.

$$
\begin{aligned}
& \mathrm{Ra}_{\mathrm{TOA}}=\mathrm{SW}_{\mathrm{TOA}}+\mathrm{LW}_{\mathrm{TOA}} \\
& \mathrm{Ra}_{\mathrm{BOT}}=\mathrm{SW}_{\mathrm{BOT}}+\mathrm{LW}_{\mathrm{BOT}} \\
& \mathrm{Ra}_{\mathrm{ATM}}=\mathrm{SW}_{\mathrm{ATM}}+\mathrm{LW}_{\mathrm{ATM}} .
\end{aligned}
$$

\subsubsection{Clear-sky radiative forcing}

The radiative forcing induced by dust shown in Fig. 7 is also referred to as clear-sky radiative forcing and is due to the reflection, absorption, and emission of radiation by dust particles suspended in the atmosphere.

The clear-sky downwelling SW radiation at the top of the atmosphere is slightly reduced over most land areas of East 

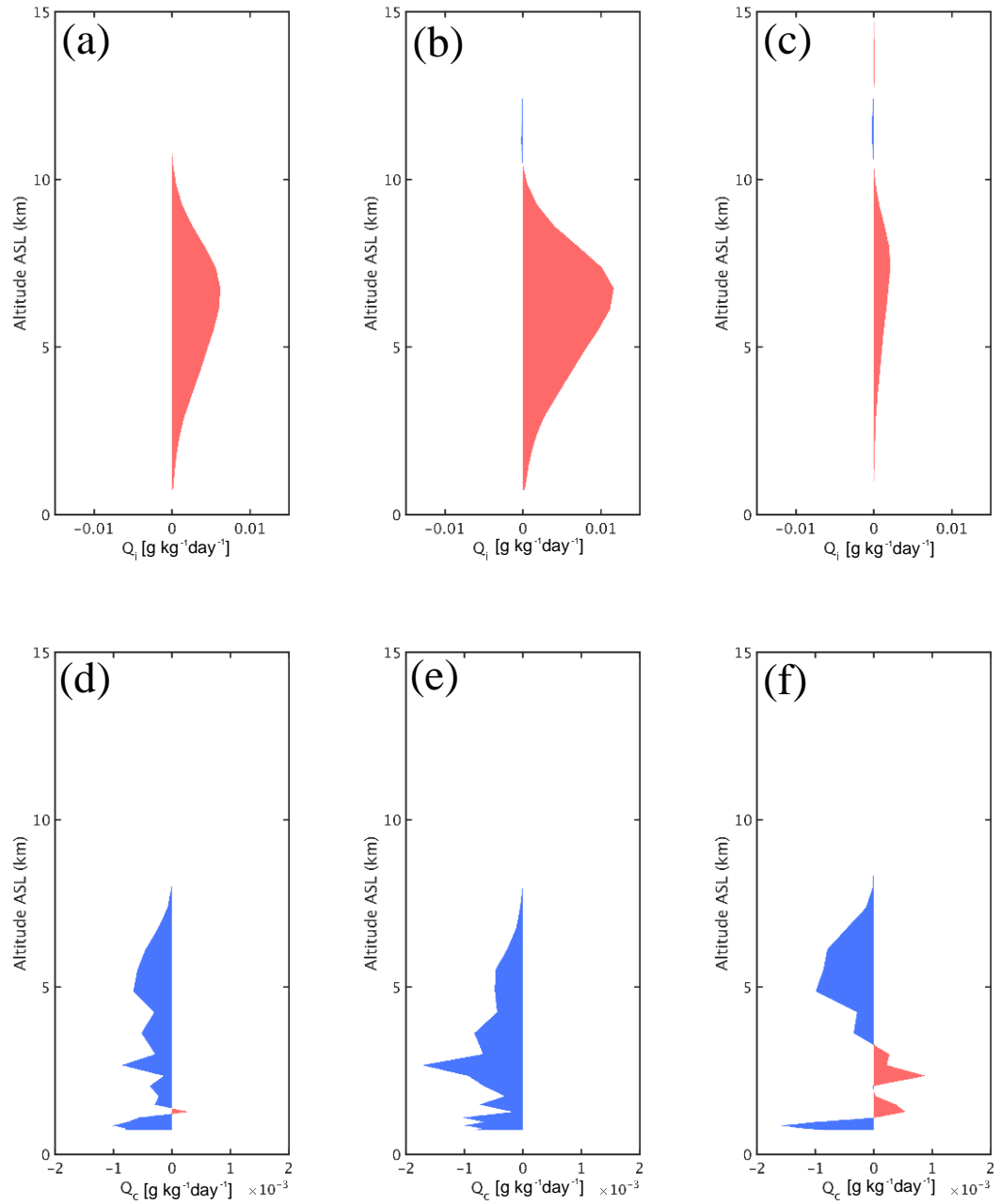

Figure 6. Vertical profile of the modification of cloud ice $(\mathbf{a}-\mathbf{c})$ and cloud water content (e-f) induced by dust over the entire simulation domain (left panels), over land (middle panels), and over ocean (right panels).

Table 2. WRF-Chem-simulated SW, LW, and net radiative forcing $\left(\mathrm{W} \mathrm{m}^{-2}\right)$ induced by dust over East Asia at TOA, BOT, and ATM.

\begin{tabular}{lrrr|rrr}
\hline & \multicolumn{3}{c|}{ Clear sky } & \multicolumn{3}{c}{ All sky } \\
\cline { 2 - 7 } & SW & LW & Net & SW & LW & Net \\
\hline TOA (+down) & -0.63 & 0.18 & -0.45 & -0.49 & 0.31 & -0.18 \\
ATM (+warm) & 1.56 & -1.26 & 0.30 & 1.44 & -0.88 & 0.57 \\
BOT (+down) & -2.19 & 1.44 & -0.75 & -1.94 & 1.19 & -0.75
\end{tabular}

SW: shortwave radiative forcing; LW: longwave radiative forcing; Net: net radiative forcing. TOA: radiative forcing at the top of the atmosphere; ATM: radiative effect within the atmosphere; BOT: radiative effect at the bottom of the atmosphere.

Asia (Fig. 7a), indicating that the upwelling SW radiation at the top of the atmosphere increases due to the reflection and scattering of SW radiation by dust particles. The clear-sky $\mathrm{SW}$ radiative forcing at the bottom of the atmosphere is negative over most of East Asia (Fig. 7g), especially over dust source regions, which suggests that the solar radiation that reaches the Earth's surface is substantially reduced through the absorption by dust particles suspended in the atmosphere. The absorption of solar radiation by dust particles heats up the dust layers, leading to a significant net warming effect within the atmosphere (Fig. 7d). Averaged over the entire simulation domain, the $\mathrm{SW}$ radiative forcing over East Asia 


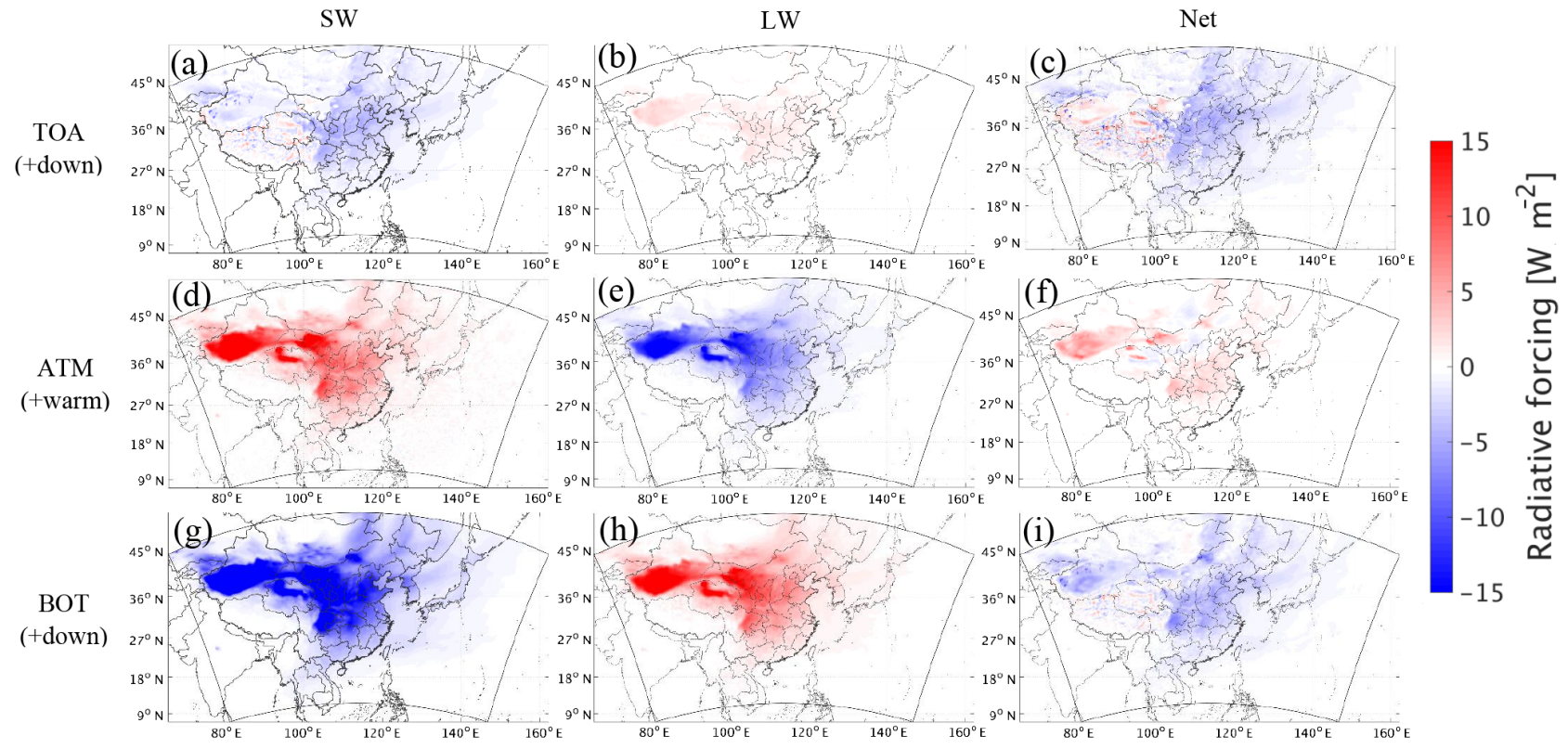

Figure 7. Spatial distributions of the clear-sky SW (left panels), LW (middle panels), and net (right panels) radiative forcing at the top of the atmosphere (TOA, a-c), within the atmosphere (ATM, d-f), and at the bottom of the atmosphere (BOT, $\mathbf{g}-\mathbf{i}$ ).

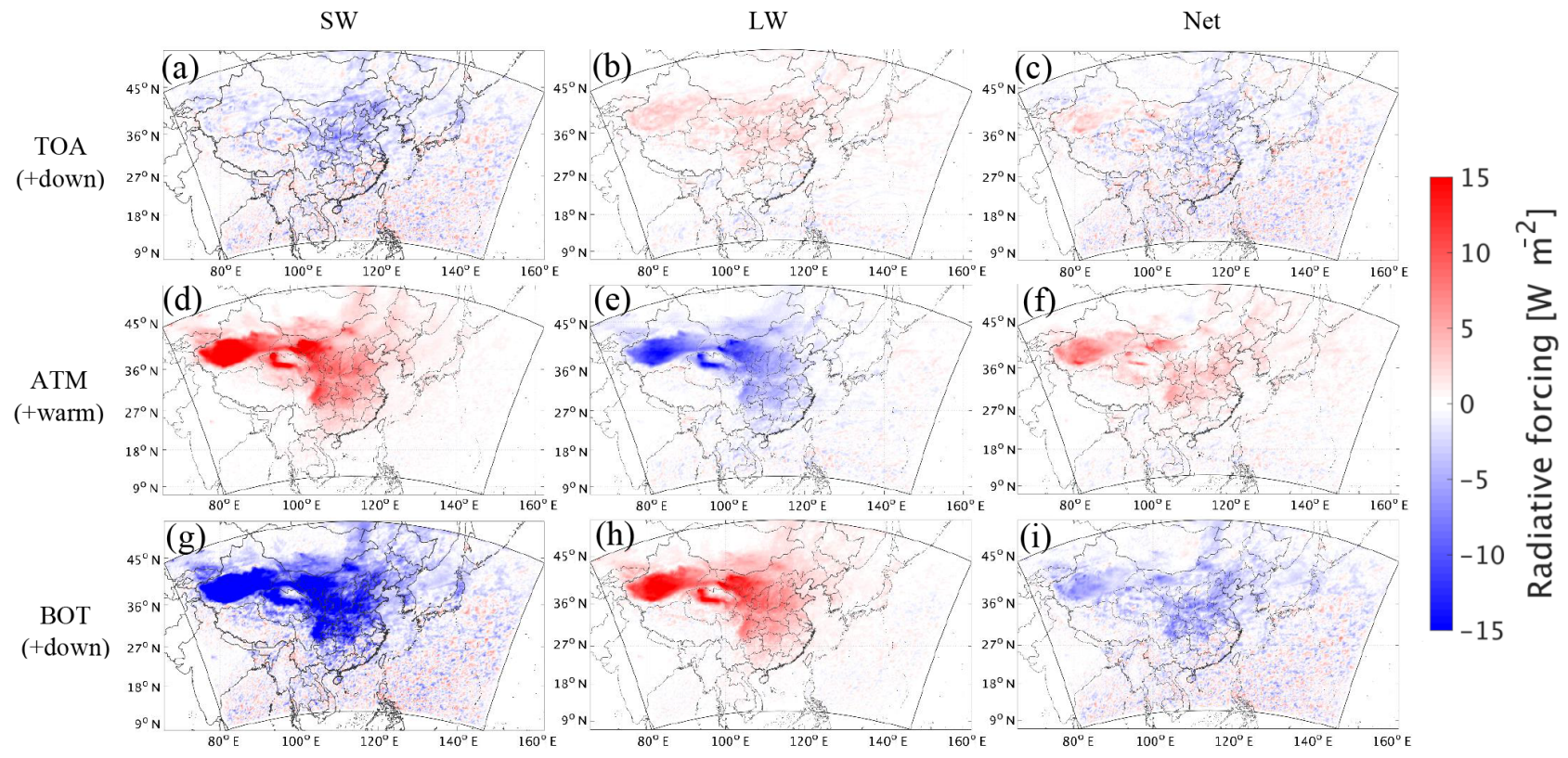

Figure 8. Spatial distributions of the all-sky SW (left panels), LW (middle panels), and net (right panels) radiative forcing at the top of the atmosphere (TOA, a-c), within the atmosphere (ATM, $\mathbf{d}-\mathbf{f})$, and at the bottom of the atmosphere (BOT, $\mathbf{g}-\mathbf{i}$ ).

is $-0.63 \mathrm{~W} \mathrm{~m}^{-2}$ at the top of the atmosphere, $-2.19 \mathrm{~W} \mathrm{~m}^{-2}$ at the bottom of the atmosphere, and $1.56 \mathrm{~W} \mathrm{~m}^{-2}$ within the atmosphere, accounting for $0.19,0.87$, and $1.98 \%$ of the total clear-sky radiation budget in these three zones, respectively, as shown in Table 2.

In Fig. 7b, the clear-sky downwelling LW radiation at the top of the atmosphere is slightly increased over dust source regions and downstream areas due to the absorption of LW radiation by the thick dust layer with a large fraction of coarse particles in the atmosphere. In comparison, the clearsky downwelling LW radiation is reduced at the bottom of the atmosphere (Fig. 7h), which is attributed to the Earth's surface being cooled as it receives less solar radiation (Fig. $7 \mathrm{~g}$ ). Combining the LW radiative forcing at the top of the atmo- 
sphere and at the bottom of the atmosphere, there is a net negative LW radiative forcing within the atmosphere (Fig. 7e). Overall, the mean LW radiative forcing averaged over the entirety of East Asia is $0.18 \mathrm{~W} \mathrm{~m}^{-2}$ at the top of the atmosphere, $1.44 \mathrm{~W} \mathrm{~m}^{-2}$ at the bottom of the atmosphere, and $-1.94 \mathrm{~W} \mathrm{~m}^{-2}$ within the atmosphere, accounting for 0.07 , 1.57 , and $0.74 \%$ of the total clear-sky radiation budget in those three zones, respectively.

Combining the SW and LW radiative forcing, the net downwelling clear-sky radiation at the top of the atmosphere is reduced over most of East Asia (Fig. 7c). The downwelling clear-sky net radiation at the bottom of the atmosphere is also reduced over most parts of East Asia, especially over dust source regions and downstream areas (Fig. 7i), leading to a net warming effect within the atmosphere (Fig. 7f), which is slightly smaller than the warming caused by SW radiative forcing (Fig. 7d). The net radiative forcing is $-0.45 \mathrm{~W} \mathrm{~m}^{-2}$ at the top of the atmosphere, $-0.75 \mathrm{~W} \mathrm{~m}^{-2}$ at the bottom of the atmosphere, and $0.30 \mathrm{~W} \mathrm{~m}^{-2}$ within the atmosphere, accounting for $0.67,0.47$, and $0.33 \%$ of the total clear-sky radiation budget in those three zones.

\subsubsection{All-sky radiative forcing}

The all-sky radiative forcing induced by dust shown in Fig. 8 is the total radiative forcing, including the radiative forcing directly induced by dust displayed in Fig. 7, and that induced by the cloud radiative effect enhanced by dust.

As SW radiation is not sensitive to ice crystals in the atmosphere, the all-sky downwelling SW radiation shows a smaller reduction at the top (Fig. 8a) and the bottom (Fig. 8g) of the atmosphere over dust sources and downstream areas compared to the clear-sky case. The perturbations of all-sky SW radiation over the southern part of the simulation domain and the Pacific Ocean in Fig. 8a and g are likely due to the fluctuation of cloud cover. Similarly, the all-sky SW radiative radiation shows a warming effect within the atmosphere (Fig. 8d), with an identical magnitude and spatial distribution to the clear-sky case, as the warming is mostly attributed to the absorption of SW radiation by dust particles. Averaged over the entire simulation domain, the mean SW radiative forcing is $-0.49 \mathrm{~W} \mathrm{~m}^{-2}$ at the top of the atmosphere, $-1.94 \mathrm{~W} \mathrm{~m}^{-2}$ at the bottom of the atmosphere, and $1.44 \mathrm{~W} \mathrm{~m}^{-2}$ within the atmosphere (Table 2), accounting for $0.17,0.93$, and $1.81 \%$ of the total all-sky radiation budget in the three zones, respectively.

Compared to the clear-sky case, the positive LW radiative forcing at the top of the atmosphere is slightly increased over dust sources and downstream land areas over East Asia (Fig. 8b), indicating less upwelling LW radiation at the top of the atmosphere. This is likely caused by the combination of the lower surface temperature due to less solar radiation reaching the Earth's surface and the absorption of LW radiation by more ice clouds induced by dust plumes over these areas. The absorption of LW radiation by more ice clouds also leads to less cooling within the atmosphere (Fig. 8e) compared to the clear-sky case. Moreover, a greater cloud amount results in an increase in surface temperature, leading to more upwelling LW radiation emitted by the surface and thus a smaller positive LW radiative forcing at the bottom of the atmosphere (Fig. 8h). As shown in Table 2, the mean allsky LW radiative forcing over the entire simulation domain is $0.31 \mathrm{~W} \mathrm{~m}^{-2}$ at the top of the atmosphere, $1.19 \mathrm{~W} \mathrm{~m}^{-2}$ at the bottom of the atmosphere, and $-1.26 \mathrm{~W} \mathrm{~m}^{-2}$ within the atmosphere, accounting for $0.07,1.57$, and $0.74 \%$ of the total all-sky radiation budget in the three zones, respectively.

Summing the SW and LW radiative forcing, the net downwelling all-sky radiation at the top of the atmosphere is generally increased over dust sources, whereas it is reduced over the downstream land areas (Fig. 8c). By contrast, the net downwelling all-sky net radiation at the bottom of the atmosphere is reduced significantly over most land areas over East Asia (Fig. 8i). Radiative forcing results in pronounced warming within the atmosphere over East Asia as a whole (Fig. 8f). Averaged over the simulation domain, the net all-sky radiative forcing is $-0.18,-0.75$, and $0.57 \mathrm{~W} \mathrm{~m}^{-2}$ at the top of the atmosphere, at the bottom of the atmosphere, and within the atmosphere during the simulation period, accounting for $0.38,0.56$, and $0.66 \%$ of the total net radiation budget in those three zones, respectively.

In summary, the direct radiative effect of dust combined with the cloud radiative effect enhanced by dust generally causes a net loss of radiation at the Earth's surface, but a net gain within the atmosphere, leading to a cooling at the surface and lower troposphere and a warming in middle to upper troposphere. Nevertheless, as ice clouds enhanced by dust are thin clouds, which contribute little to the modifications of both LW and SW radiation, the radiative forcing induced by the indirect effects of dust is much less significant than that by the direct radiative effect of dust; therefore, the dust-induced radiative forcing over East Asia is dominated by the direct radiative effect of dust. However, the perturbation of the radiation budget, especially over the south part of the simulation domain and the Pacific Ocean, is likely due to the fluctuation of the liquid cloud amount. On average, the radiative effect caused by the increase in ice clouds compensates with that resulting from the decrease in liquid clouds, leaving comparable modifications of the net radiative forcing in the clear-sky case and the all-sky case.

\subsection{Vertical temperature profile}

Due to radiative forcing induced by the effects of dust, the vertical temperature profile is modified. Figure 9 shows the modifications of the vertical temperature profiles resulting from the direct radiative effect of dust, the cloud radiative effect enhanced by dust, and the full radiative effect of dust over East Asia, over land, and over the ocean during the investigated period. 

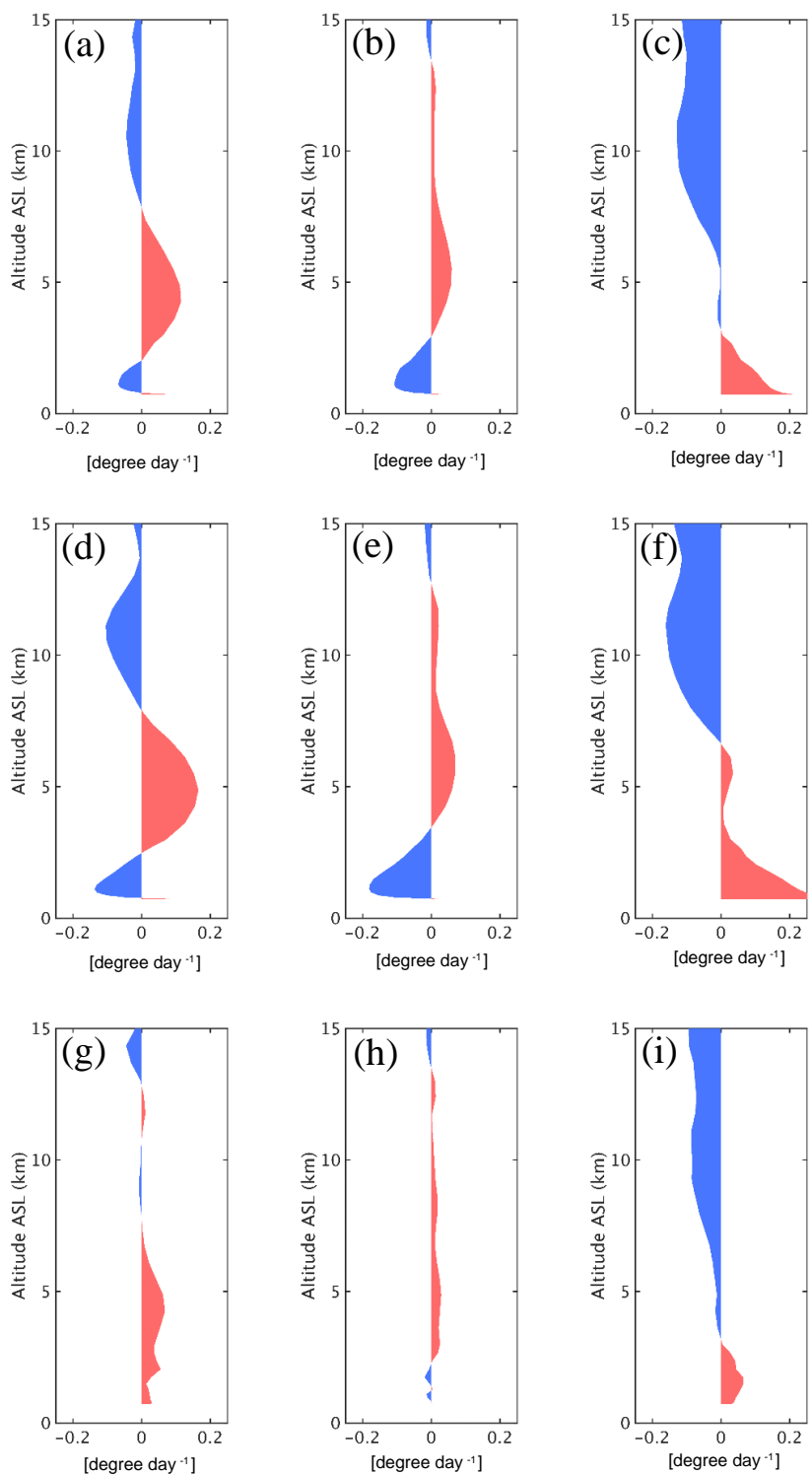

Figure 9. Modification of the vertical temperature profile induced by the full effects of dust (left panels), the direct radiative effect of dust (middle panels), and the semi-direct and indirect effects of dust (right panels) over the entire simulation domain $(\mathbf{a}-\mathbf{c})$, over land $(\mathbf{d}-$ f), and over ocean (g-i).

On average, the temperature over the simulation domain as a whole is decreased below $2 \mathrm{~km}$, increased from 2 to $7 \mathrm{~km}$, and then decreased above $7 \mathrm{~km}$ (Fig. 9a). The contributions of the direct radiative effect of dust and dust-enhanced cloud radiative effect to the vertical temperature modification are shown in Fig. $9 \mathrm{~b}$ and c. The direct radiative effect of dust (Fig. 9b) results in a decrease in temperature below $3 \mathrm{~km}$ and an increase from 3 to $14 \mathrm{~km}$. In contrast, the pattern of the vertical temperature modification caused by the dust-enhanced cloud radiative effect (Fig. 9c) is opposite to that caused by the direct effect of dust. The temperature is increased from the surface to $3 \mathrm{~km}$ and then decreased from 3 to $15 \mathrm{~km}$.

As the radiative forcing induced by dust over land differs from that over the ocean, the effects on the vertical temperature profile require further discussion. The modifications of the vertical temperature profile over land induced by the full effects (Fig. 6d), direct effect (Fig. 6e) and indirect effects (Fig. 6f) of dust exhibit similar distributions to those over the entire domain, but with larger magnitudes. The decrease in temperature at the lower level is composed of roughly equal contributions from the direct radiative effect and the dustenhanced cloud radiative effect. The decrease in temperature at lower layers is mainly attributable to the negative SW radiative forcing at the surface induced by dust, and the increase in temperature at the mid-troposphere is due to the absorption of SW radiation by dust plumes. The decrease in temperature at the upper troposphere might be due to the fact that the enhancement of ice clouds in the middle to upper troposphere prevents the upwelling LW radiation from being absorbed by ice clouds at higher altitudes.

The modification of the vertical temperature profile over the ocean is different from that over land. The temperature is increased from the surface to the mid-troposphere (Fig. 9g), which is caused by two factors. One is the increase in temperature at lower layers (Fig. 9i) attributed to more absorption of LW radiation and latent heat released by the enhancement of low clouds. The other is the increase in temperature at the mid-troposphere (Fig. 9h) caused by the absorption of SW radiation by dust plumes.

\subsection{Atmospheric stability}

As discussed above, the radiative forcing and the redistribution of atmospheric water content induced by dust result in a modification of the vertical temperature profile over East Asia. The corresponding shift of the thermal energy in the atmosphere eventually leads to a modification of the atmospheric stability over this region.

The $\mathrm{K}$ index $(\mathrm{KI})$ is a metric widely used in meteorology to evaluate atmospheric stability and is calculated with the following equation (George, 2014):

$\mathrm{KI}=T_{850}-T_{500}+\mathrm{Td}_{850}-\left(T_{700}-\mathrm{Td}_{700}\right)$,

where $T_{850}, T_{700}$, and $T_{500}$ are the respective temperatures at 850,700 , and $500 \mathrm{hPa}$, and $\mathrm{Td}_{850}$ and $\mathrm{Td}_{700}$ are the dew points at $850 \mathrm{hPa}$ and $700 \mathrm{hPa}$. The calculation of KI considers atmospheric stability as a function of the vertical temperature lapse rate, the moisture content of the lower atmosphere, and the vertical extent of the moist layer. The larger the value of KI, the more unstable the atmosphere. To evaluate the effect of dust on atmospheric stability, KI was calculated from the simulation outputs.

Figure 10 shows the spatial distributions for the mean KI from NO-DUST/CLOUD over East Asia during the simulation period, which represents the intrinsic average atmo- 


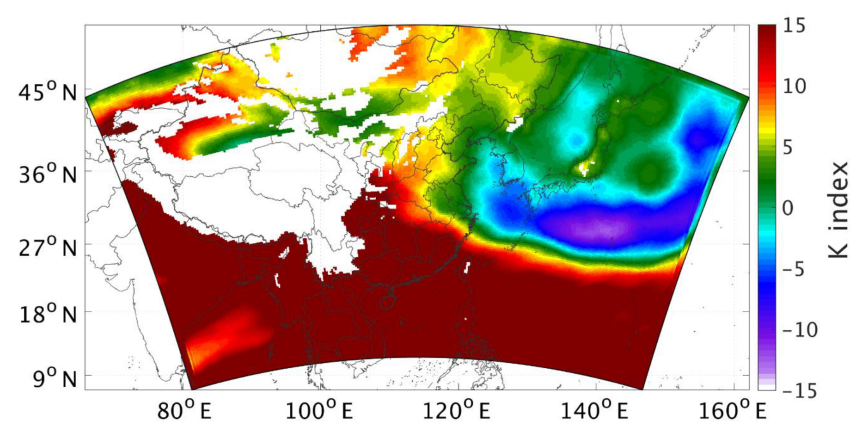

Figure 10. Spatial distributions of the monthly average $\mathrm{K}$ index from NO-DUST/CLOUD.
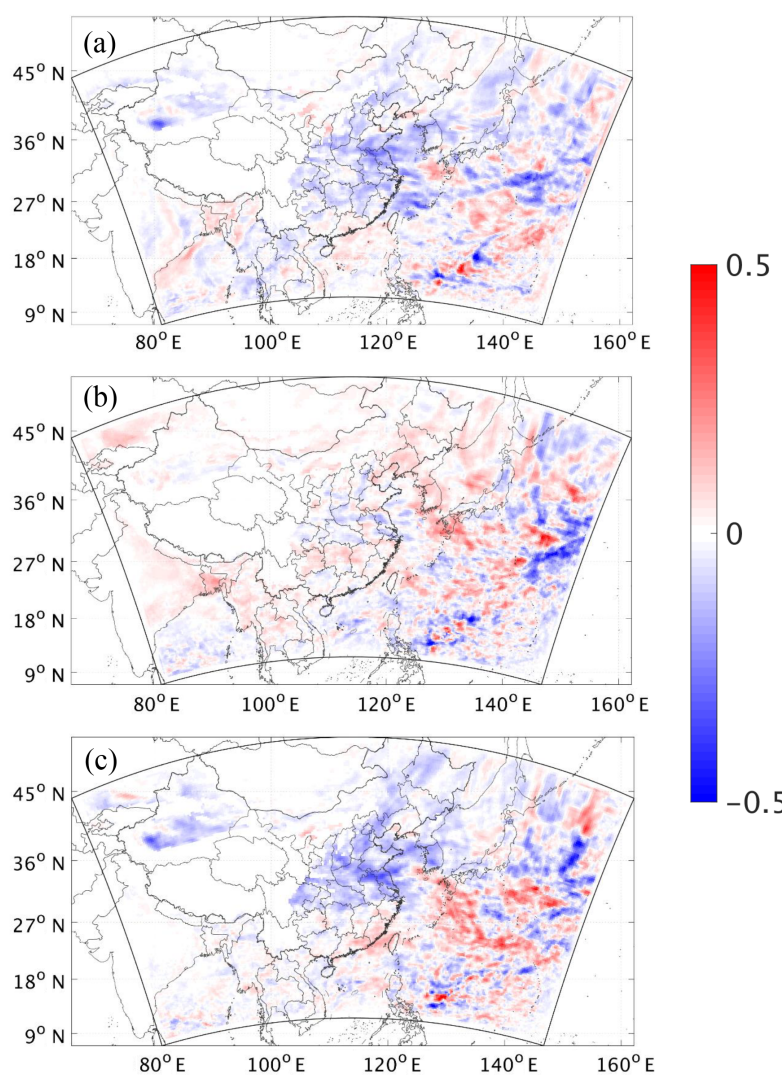

Figure 11. Spatial distributions of the modification of the K index induced by the direct radiative effect of dust (a), the semi-direct and indirect effects of dust (b), and the full effects of dust (c).

spheric stability free from the effects of dust, and Fig. 11 shows the spatial distributions for the mean difference in KI between DUST/NO-CLOUD and NO-DUST/NO-CLOUD (Fig. 11a), between DUST/CLOUD and NO-DUST/CLOUD (Fig. 11b), and between DUST/CLOUD and NO-DUST/ CLOUD (Fig. 11c). The differences represent the modification of KI induced by the direct radiative effect of dust in Fig. 11a; the indirect effects, including cloud radiative effects and the redistribution of atmospheric water content enhanced by dust, are shown in Fig. $11 \mathrm{~b}$ and the combined effects of the previous two in Fig. 11c.

As shown in Fig. 10, the mean KI over East Asia is lower in the north and increases gradually from north to south, with the highest values located over the South China Sea and Southeast Asia and the lowest values over the central to northern Pacific.

The contributions of the direct radiative effect of dust and the indirect effects of dust to the modification of the mean $\mathrm{KI}$ are shown in Fig. 11a and b. The direct radiative effect of dust inhibits atmospheric instability over most land areas, indicated by a decrease in the mean KI, as shown in Fig. 11a. However, the indirect effects of dust result in an opposite modification of the mean KI, with a slight enhancement of mean KI over most areas of the investigated domain. Upon considering the full effects of dust, the mean modification of $\mathrm{KI}$ over most land areas in East Asia is a general decrease (Fig. 11c). The largest decrease occurs over the dust source regions and central to east China and results from the vertical modification over land. In contrast, KI increases over south China and most of the southern parts of the domain due to the different effects of dust on the vertical temperature over these areas.

Overall, the atmosphere is stabilized over the dust source regions and central to east China, but destabilized over south China and most ocean areas due to the effects of dust.

\subsection{Precipitation}

The modification of atmospheric stability and the redistribution of atmospheric water content induced by dust eventually alter precipitation over East Asia. The spatial distributions for the mean precipitation rate, including total precipitation, convective precipitation, and non-convective precipitation from NO-DUST/CLOUD and DUST/CLOUD, as well as the difference between the two simulations, are shown in Fig. 12. Note that the precipitation rate shown in Fig. 12 is the mean daily precipitation rate averaged over the simulation period.

The spatial pattern of the mean total precipitation rate from NO-DUST/CLOUD shown in Fig. 12a is generally similar to that from DUST/CLOUD shown in Fig. 12b. However, Fig. $12 \mathrm{c}$ clearly shows that precipitation is modified due to the effects of dust, leading to an overall reduction of the total precipitation by as much as $1 \mathrm{~mm} \mathrm{day}^{-1}$ or more to the east of central to south China, where the main precipitation area is located, while there is an increase by up to $1 \mathrm{~mm} \mathrm{day}^{-1}$ to the west. Meanwhile, the precipitation rate over south China is slightly enhanced. The modifications of precipitation account for up to $20 \%$ of the total simulated precipitation rate over land areas in the simulation domain.

The simulated convective precipitation mostly occurs over the southern part of the simulation domain, with precipitation centers located over east and south China, the South China Sea, and Southeast Asia (Fig. 12d and e). Due to the ef- 

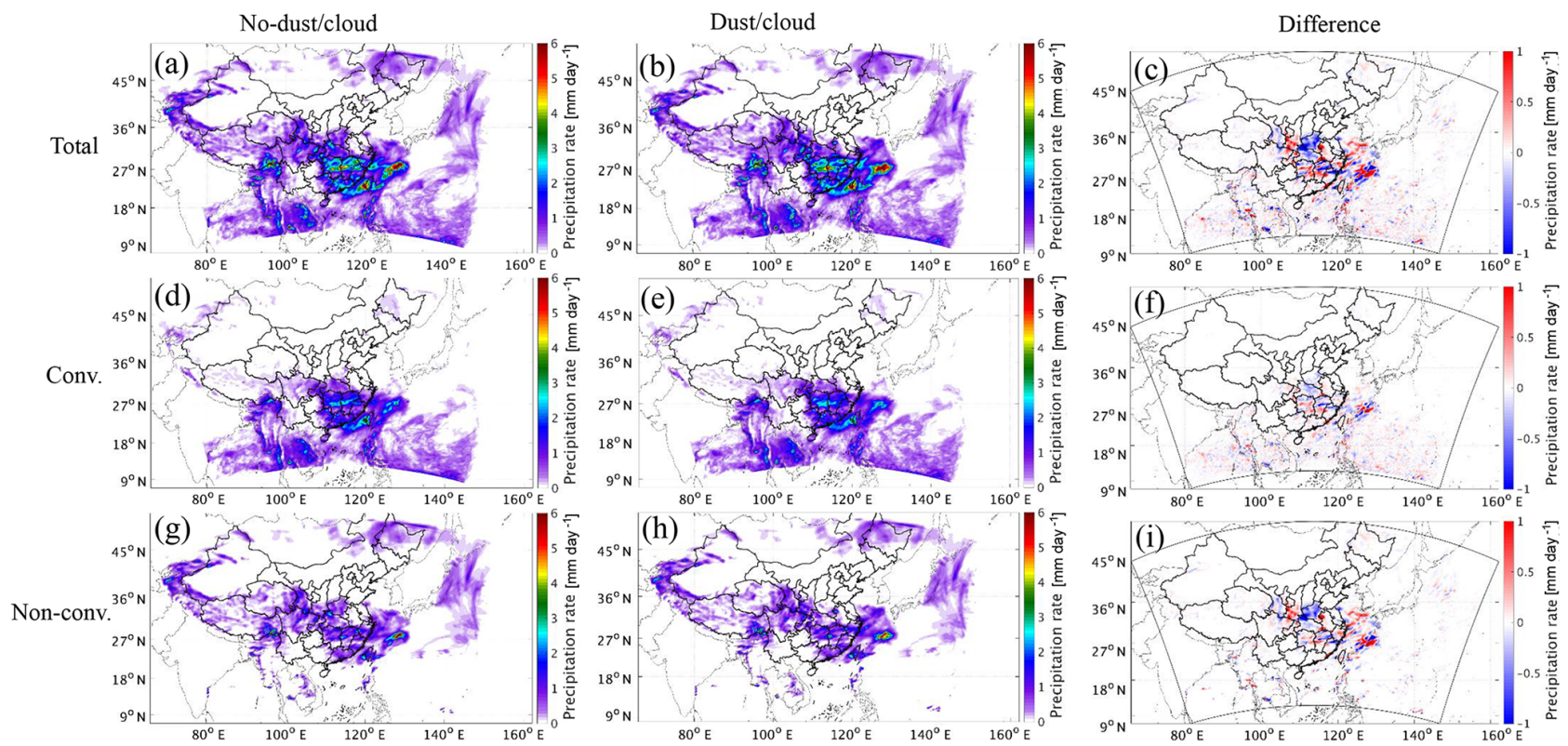

Figure 12. Spatial distributions of the average simulated total precipitation rate (a-c), convective precipitation rate (d-f), and non-convective precipitation rate (g-i) from NO-DUST/CLOUD (left panels), DUST/CLOUD (middle panels), and the difference between DUST/CLOUD and NO-DUST/CLOUD (right panels).

fects of dust, convective precipitation is enhanced over south China, but inhibited over east China (Fig. 12f). The inhibition of convective precipitation over central to east China is likely due to the general enhancement of atmospheric stability, which reduces convective motion over this region. The greater convective precipitation over south China is attributed to the more unstable atmosphere, which promotes convective motion.

Non-convective precipitation mainly occurs at the western rim of the Taklimakan Desert, northeast China, Japan, and the areas between 27 and $36^{\circ} \mathrm{N}$ over East Asia during the simulation period. The spatial distribution of the nonconvective precipitation rate produced in DUST/CLOUD (Fig. 12h) is similar to that produced in NO-DUST/CLOUD (Fig. 12g). However, Fig. 12i shows that the non-convective precipitation rate is modified upon considering the effects of dust. The non-convective precipitation band over central China exhibits a shift of location, with less precipitation to the east and west, but more in the middle. This is likely due to the modification of liquid clouds over the same area, with fewer clouds to the east and west, but more in the middle (Fig. 5f). Similarly, the enhancement or inhibition of nonconvective precipitation over south to east China is also related to the perturbation of the cloud amount over these areas. On average, the amount of non-convective precipitation is increased or decreased by up to $20 \%$ at the main precipitation regions.

To summarize, the total amount of precipitation over the entire investigated domain remains the same by taking the effects of dust into account; however, the locations of the precipitation might be shifted, and precipitation can be enhanced or inhibited by up to $20 \%$ over regions with relatively abundant precipitation during the investigated period, such as central to east China and south China.

\section{Conclusions}

By applying the updated WRF-Chem, which is capable of evaluating the indirect effects of dust along with the direct effect in dust simulations, the full effects of dust, including direct radiative, cloud radiative, and indirect microphysical effects, on the meteorological field over East Asia during March and April 2012 were quantified and discussed.

By considering the effects of dust in the simulation, the atmospheric IWP is substantially increased from west China to the northwest Pacific Ocean, which are the dust sources and their downstream areas with abundant dust particles available to serve as IN. By contrast, the atmospheric CWP is generally reduced over the same areas, while it shows perturbations over the rest of the areas in East Asia. Vertically, the effects of dust result in a general increase in cloud ice and a decrease in cloud water over East Asia as a whole, as the increase in ice clouds is mainly concentrated at the middle to upper troposphere. However, the decrease in liquid clouds mostly occurs at the low to middle troposphere. The increase in ice clouds is due to the enhancement of the ice nucleation process with abundant dust particles serving as IN. The reduction in liquid clouds is attributed to two factors. One is the burning effect of dust. Dust particles in the atmosphere 
absorb radiation and warm up the surrounding environment, leading to a much greater saturation pressure required for atmospheric water vapor to form clouds and a much faster evaporation rate of cloud droplets. The other factor is that the ice nucleation process enhanced by dust facilitates the freezing of atmospheric supercooled water droplets into ice crystals.

For the radiative forcing induced by dust, the direct radiative effect of dust combined with the dust-enhanced cloud radiative effect causes a net loss of radiation at the Earth's surface, but a net gain of radiation within the atmosphere, leading to cooling at the surface and lower troposphere and warming in the middle to upper troposphere. The radiative forcing caused by the direct radiative effect of dust is greater than that induced by the dust-enhanced cloud radiative effect over land areas, as the thin ice clouds enhanced by dust particles have limited impacts on altering the radiation budget.

The modification of clouds, including ice and liquid clouds, as well as the radiative forcing induced by dust lead to an altering of the vertical temperature profile. Consequently, the atmosphere is stabilized over most land areas, but destabilized over south China and most oceanic areas.

Convective precipitation is inhibited over south China due enhanced atmospheric stability, while it is enhanced over central China as a result of the more unstable atmosphere. The modification of cloud amount results in a shift of locations of non-convective precipitation over China. On average, the total amount of precipitation over the entire investigated domain remains the same by taking the effects of dust into account; however, the locations of precipitation might be shifted, and precipitation can be enhanced or inhibited by up to $20 \%$ over particular regions with relatively abundant precipitation during the investigated period.

Data availability. The WRF-Chem outputs are available from the authors upon request (lsu@connect.ust.hk). The China meteorological dataset can be obtained freely from the website of the Data Assimilation and Modeling Center for Tibetan Multi-spheres, Institute of Tibetan Plateau Research, Chinese Academy of Sciences (http://westdc.westgis.ac.cn/data/ 7a35329c-c53f-4267-aa07-e0037d913a21).

Author contributions. LS performed the research. LS and JCHF wrote the paper.

Competing interests. The authors declare that they have no conflict of interest.

Acknowledgements. We would like to acknowledge the principal investigators and their staff from the Data Assimilation and Modeling Center for Tibetan Multi-spheres, Institute of Tibetan Plateau Research, Chinese Academy of Sciences, for the provision of the China Meteorological Forcing Dataset used in this study for model validation. Lin Su would like to thank Georg Grell, Stuart McKeen, and Ravan Ahmandov from the Earth System Research Laboratory, U.S. National Oceanic and Atmospheric Administration, for insightful discussions. All data used in this paper are properly cited and referred to in the reference list. All data shown in the results are available upon request. This work was supported by NSFC/RGC grant no. HKUST631/05, NSFC-FD grant U1033001, and RGC grant 16303416.

Edited by: Corinna Hoose

Reviewed by: two anonymous referees

\section{References}

Atkinson, J. D., Murray, B. J., Woodhouse, M. T., Whale, T. F., Baustian, K. J., Carslaw, K. S., Dobbie, S., O'sullivan, D., and Malkin, T. L.: The importance of feldspar for ice nucleation by mineral dust in mixed-phase clouds, Nature, 498, 355-358, 2013.

Bi, J., Huang, J., Fu, Q., Ge, J., Shi, J., Zhou, T., and Zhang, W.: Field measurement of clear-sky solar irradiance in Badain Jaran Desert of Northwestern China, J. Quant. Spectrosc. Radiat. Transf., 122, 194-207, 2013.

Broadley, S. L., Murray, B. J., Herbert, R. J., Atkinson, J. D., Dobbie, S., Malkin, T. L., Condliffe, E., and Neve, L.: Immersion mode heterogeneous ice nucleation by an illite rich powder representative of atmospheric mineral dust, Atmos. Chem. Phys., 12, 287-307, https://doi.org/10.5194/acp-12-287-2012, 2012.

Chen, Y., Yang, K., He, J., Qin, J., Shi, J., Du, J., and He, Q.: Improving land surface temperature modeling for dry land of China, J. Geophys. Res.-Atmos., 116, https://doi.org/10.1029/2011JD015921, 2011.

Chen, S., Huang, J., Kang, L., Wang, H., Ma, X., He, Y., Yuan, T., Yang, B., Huang, Z., and Zhang, G.: Emission, transport, and radiative effects of mineral dust from the Taklimakan and Gobi deserts: comparison of measurements and model results, Atmos. Chem. Phys., 17, 2401-2421, https://doi.org/10.5194/acp17-2401-2017, 2017.

Connolly, P. J., Möhler, O., Field, P. R., Saathoff, H., Burgess, R., Choularton, T., and Gallagher, M.: Studies of heterogeneous freezing by three different desert dust samples, Atmos. Chem. Phys., 9, 2805-2824, https://doi.org/10.5194/acp-9-2805-2009, 2009.

Data Assimilation and Modeling Center for Tibetan Multispheres, Institute of Tibetan Plateau Research, Chinese Academy of Sciences, available at: (http://westdc.westgis.ac.cn/data/ 7a35329c-c53f-4267-aa07-e0037d913a21, last access: 3 August 2018.

DeMott, P. J., Sassen, K., Poellot, M. R., Baumgardner, D., Rogers, D. C., Brooks, S. D., Prenni, A. J., and Kreidenweis, S. M.: African dust aerosols as atmospheric ice nuclei, Geophys. Res. Lett., 30, https://doi.org/10.1029/2003GL017410, 2003.

DeMott, P. J., Prenni, A. J., McMeeking, G. R., Sullivan, R. C., Petters, M. D., Tobo, Y., Niemand, M., Möhler, O., Snider, J. R., Wang, Z., and Kreidenweis, S. M.: Integrating laboratory and field data to quantify the immersion freezing ice nucleation activity of mineral dust particles, Atmos. Chem. Phys., 15, 393-409, https://doi.org/10.5194/acp-15-393-2015, 2015. 
Ge, J., Su, J., Ackerman, T., Fu, Q., Huang, J., and Shi, J.: Dust aerosol optical properties retrieval and radiative forcing over northwestern China during the 2008 China US joint field experiment, J. Geophys. Res.-Atmos., 115, https://doi.org/10.1029/2009JD013263, 2010.

George, J. J.: Weather forecasting for aeronautics, Academic Press, 673, 2014.

Ginoux, P., Chin, M., Tegen, I., Prospero, J. M., Holben, B., Dubovik, O., and Lin, S. J.: Sources and distributions of dust aerosols simulated with the GOCART model, J. Geophys. Res.Atmos., 106, 20255-20273, 2001.

Ginoux, P., Prospero, J. M., Torres, O., and Chin, M.: Long-term simulation of global dust distribution with the GOCART model: correlation with North Atlantic Oscillation, Environ. Model. Softw., 19, 113-128, 2004.

Grell, G. A. and Freitas, S. R.: A scale and aerosol aware stochastic convective parameterization for weather and air quality modeling, Atmos. Chem. Phys., 14, 5233-5250, https://doi.org/10.5194/acp-14-5233-2014, 2014.

Hansen, J., Sato, M., and Ruedy, R.: Radiative forcing and climate response, J. Geophys. Res.-Atmos., 102, 6831-6864, 1997.

Hartmann, D., Tank, A., and Rusticucci, M.: IPCC fifth assessment report, climate change 2013: The physical science basis, IPCC AR5, 31-39, 2013.

Hoose, C., Lohmann, U., Erdin, R., and Tegen, I.: The global influence of dust mineralogical composition on heterogeneous ice nucleation in mixed-phase clouds, Environ. Res. Lett., 3, 025003 , https://doi.org/10.1088/1748-9326/3/2/025003, 2008.

Huang, J., Fu, Q., Su, J., Tang, Q., Minnis, P., Hu, Y., Yi, Y., and Zhao, Q.: Taklimakan dust aerosol radiative heating derived from CALIPSO observations using the Fu-Liou radiation model with CERES constraints, Atmos. Chem. Phys., 9, 4011-4021, https://doi.org/10.5194/acp-9-4011-2009, 2009.

Iacono, M. J., Delamere, J. S., Mlawer, E. J., Shephard, M. W., Clough, S. A., and Collins, W. D.: Radiative forcing by long-lived greenhouse gases: Calculations with the AER radiative transfer models, J. Geophys. Res.-Atmos., 113, https://doi.org/10.1029/2008JD009944, 2008.

Janjić, Z. I.: The step-mountain eta coordinate model: Further developments of the convection, viscous sublayer, and turbulence closure schemes, Mon. Weather Rev., 122, 927-945, 1994.

Janjić, Z. I.: Nonsingular implementation of the Mellor-Yamada level 2.5 scheme in the NCEP Meso model, NCEP office note, 437, 1-61, 2002.

Kang, J. Y., Yoon, S. C., Shao, Y., and Kim, S. W.: Comparison of vertical dust flux by implementing three dust emission schemes in WRF/Chem, J. Geophys. Res.-Atmos., 116, https://doi.org/10.1029/2010JD014649, 2011.

Karydis, V., Kumar, P., Barahona, D., Sokolik, I., and Nenes, A.: On the effect of dust particles on global cloud condensation nuclei and cloud droplet number, J. Geophys. Res.-Atmos., 116, https://doi.org/10.1029/2011JD016283, 2011.

Koehler, K. A., Kreidenweis, S. M., DeMott, P. J., Petters, M. D., Prenni, A. J., and Möhler, O.: Laboratory investigations of the impact of mineral dust aerosol on cold cloud formation, Atmos. Chem. Phys., 10, 11955-11968, https://doi.org/10.5194/acp-1011955-2010, 2010.
Koop, T., Luo, B., Tsias, A., and Peter, T.: Water activity as the determinant for homogeneous ice nucleation in aqueous solutions, Nature, 406, 611-614, 2000.

Lacis, A.: Climate forcing, climate sensitivity, and climate response: A radiative modeling perspective on atmospheric aerosols, Aerosol Forc. Climate, 17, 11-42, 1995.

Liu, Y., Huang, J., Shi, G., Takamura, T., Khatri, P., Bi, J., Shi, J., Wang, T., Wang, X., and Zhang, B.: Aerosol optical properties and radiative effect determined from sky-radiometer over Loess Plateau of Northwest China, Atmos. Chem. Phys., 11, 1145511463, https://doi.org/10.5194/acp-11-11455-2011, 2011 a.

Liu, Zheng, Y., Li, Z., Flynn, C., Welton, E. J., and Cribb, M.: Transport, vertical structure and radiative properties of dust events in southeast China determined from ground and space sensors, Atmos. Environ., 45, 6469-6480, 2011 b.

Lohmann, U. and Feichter, J.: Global indirect aerosol effects: a review, Atmos. Chem. Phys., 5, 715-737, https://doi.org/10.5194/acp-5-715-2005, 2005.

Lohmann, U., and Diehl, K.: Sensitivity studies of the importance of dust ice nuclei for the indirect aerosol effect on stratiform mixedphase clouds, J. Atmos. Sci., 63, 968-982, 2006.

Mallet, M., Tulet, P., Serça, D., Solmon, F., Dubovik, O., Pelon, J., Pont, V., and Thouron, O.: Impact of dust aerosols on the radiative budget, surface heat fluxes, heating rate profiles and convective activity over West Africa during March 2006, Atmos. Chem. Phys., 9, 7143-7160, https://doi.org/10.5194/acp-9-7143-2009, 2009.

Mlawer, E. J., Taubman, S. J., Brown, P. D., Iacono, M. J., and Clough, S. A.: Radiative transfer for inhomogeneous atmospheres: RRTM, a validated correlated k model for the longwave, J. Geophys. Res.-Atmos., 102, 16663-16682, 1997.

Nabat, P., Somot, S., Mallet, M., Michou, M., Sevault, F., Driouech, F., Meloni, D., di Sarra, A., Di Biagio, C., Formenti, P., Sicard, M., Léon, J.-F., and Bouin, M.-N.: Dust aerosol radiative effects during summer 2012 simulated with a coupled regional aerosol-atmosphere-ocean model over the Mediterranean, Atmos. Chem. Phys., 15, 3303-3326, https://doi.org/10.5194/acp15-3303-2015, 2015a.

Nabat, P., Somot, S., Mallet, M., Sevault, F., Chiacchio, M., and Wild, M.: Direct and semi-direct aerosol radiative effect on the Mediterranean climate variability using a coupled regional climate system model, Clim. Dynam., 44, 1127-1155, 2015 b.

Palacios, L., Baró, R., and Jiménez-Guerrero, P.: An on-line modelling study of the direct effect of atmospheric aerosols over Europe, Física de la Tierra, 27, 155-170, 2015.

Peckham, S. E., Grell, G., McKeen, S. A., Ahmadov, R., Wong, K. Y., Barth, M., Pfister, G., Wiedinmyer, C., Fast, J. D., and Gustafson, W. I.: WRF-Chem version 3.8. 1 user's guide, 2017.

Perlwitz, J., and Miller, R. L.: Cloud cover increase with increasing aerosol absorptivity: A counterexample to the conventional semidirect aerosol effect, J. Geophys. Res.-Atmos., 115, https://doi.org/10.1029/2009JD012637, 2010.

Phillips, V. T., DeMott, P. J., and Andronache, C.: An empirical parameterization of heterogeneous ice nucleation for multiple chemical species of aerosol, J. Atmos. Sci., 65, 2757-2783, 2008.

Pinker, R. and Laszlo, I.: Modeling surface solar irradiance for satellite applications on a global scale, J. Appl. Meteorol., 31, 194-211, 1992. 
Rodell, M., Houser, P., Jambor, U., Gottschalck, J., Mitchell, K., Meng, C., Arsenault, K., Cosgrove, B., Radakovich, J., and Bosilovich, M.: The global land data assimilation system, B. Am. Meteorol. Soc., 85, 381-394, 2004.

Sassen, K.: Indirect climate forcing over the western US from Asian dust storms, Geophys. Res. Lett., 29, https://doi.org/10.1029/2001GL014051, 2002.

Sassen, K., DeMott, P. J., Prospero, J. M., and Poellot, M. R.: Saharan dust storms and indirect aerosol effects on clouds: CRYSTAL FACE results, Geophys. Res. Lett., 30, https://doi.org/10.1029/2003GL017371, 2003.

Satheesh, S., Deepshikha, S., and Srinivasan, J.: Impact of dust aerosols on Earth-atmosphere clear sky albedo and its short wave radiative forcing over African and Arabian regions, Int. J. Remote Sens., 27, 1691-1706, 2006.

Seigel, R. B., van den Heever, S. C., and Saleeby, S. M.: Mineral dust indirect effects and cloud radiative feedbacks of a simulated idealized nocturnal squall line, Atmos. Chem. Phys., 13, 44674485, https://doi.org/10.5194/acp-13-4467-2013, 2013.

Seinfeld, J. H., Carmichael, G. R., Arimoto, R., Conant, W. C., Brechtel, F. J., Bates, T. S., Cahill, T. A., Clarke, A. D., Doherty, S. J., and Flatau, P. J.: ACE-ASIA: Regional climatic and atmospheric chemical effects of Asian dust and pollution, B. Am. Meteorol. Soc., 85, 367-380, 2004.

Shao, Y.: Simplification of a dust emission scheme and comparison with data, J. Geophys. Res.-Atmos., 109, https://doi.org/10.1029/2003JD004372, 2004.

Shao, Y., Ishizuka, M., Mikami, M., and Leys, J.: Parameterization of size resolved dust emission and validation with measurements, J. Geophys. Res.-Atmos., 116, https://doi.org/10.1029/2010JD014527, 2011.

Sheffield, J., Goteti, G., and Wood, E. F.: Development of a 50-year high-resolution global dataset of meteorological forcings for land surface modeling, J. Climate, 19, 3088-3111, 2006.

Soil Survey Staff: Soil survey manual, US Department of Agriculture, 1-503, 1993.
Solomon, S.: Climate change 2007-the physical science basis: Working group I contribution to the fourth assessment report of the IPCC, Cambridge University Press, p. 565, 2007.

Su, L. and Fung, J. C.: Sensitivities of WRF Chem to dust emission schemes and land surface properties in simulating dust cycles during springtime over East Asia, J. Geophys. Res.-Atmos., 120, 11-215, https://doi.org/10.1002/2015JD023446, 2015.

Targino, A. C., Krejci, R., Noone, K. J., and Glantz, P.: Single particle analysis of ice crystal residuals observed in orographic wave clouds over Scandinavia during INTACC experiment, Atmos. Chem. Phys., 6, 1977-1990, https://doi.org/10.5194/acp-61977-2006, 2006.

Teller, A. and Levin, Z.: The effects of aerosols on precipitation and dimensions of subtropical clouds: a sensitivity study using a numerical cloud model, Atmos. Chem. Phys., 6, 67-80, https://doi.org/10.5194/acp-6-67-2006, 2006.

Tesfaye, M., Tsidu, G. M., Botai, J., and Sivakumar, V.: Mineral dust aerosol distributions, its direct and semi-direct effects over South Africa based on regional climate model simulation, J. Arid Environ., 114, 22-40, 2015.

Thompson, G. and Eidhammer, T.: A study of aerosol impacts on clouds and precipitation development in a large winter cyclone, J. Atmos. Sci., 71, 3636-3658, 2014.

Wesely, M.: Parameterization of surface resistances to gaseous dry deposition in regional-scale numerical models, Atmos. Environ., 23, 1293-1304, 1989.

Yang, K., He, J., Tang, W., Qin, J., and Cheng, C. C.: On downward shortwave and longwave radiations over high altitude regions: Observation and modeling in the Tibetan Plateau, Agr. Forest Meteorol., 150, 38-46, 2010.

Zhang, C., Wang, M., Morrison, H., Somerville, R. C., Zhang, K., Liu, X., and Li, J. L. F.: Investigating ice nucleation in cirrus clouds with an aerosol enabled Multiscale Modeling Framework, J. Adv. Model. Earth Syst., 6, 998-1015, 2014. 